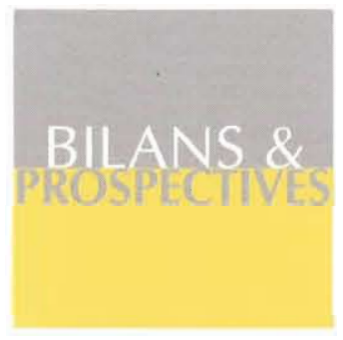

\title{
Microalgues marines Les enjeux de la recherche
}

Arnaud Muller-Feuga

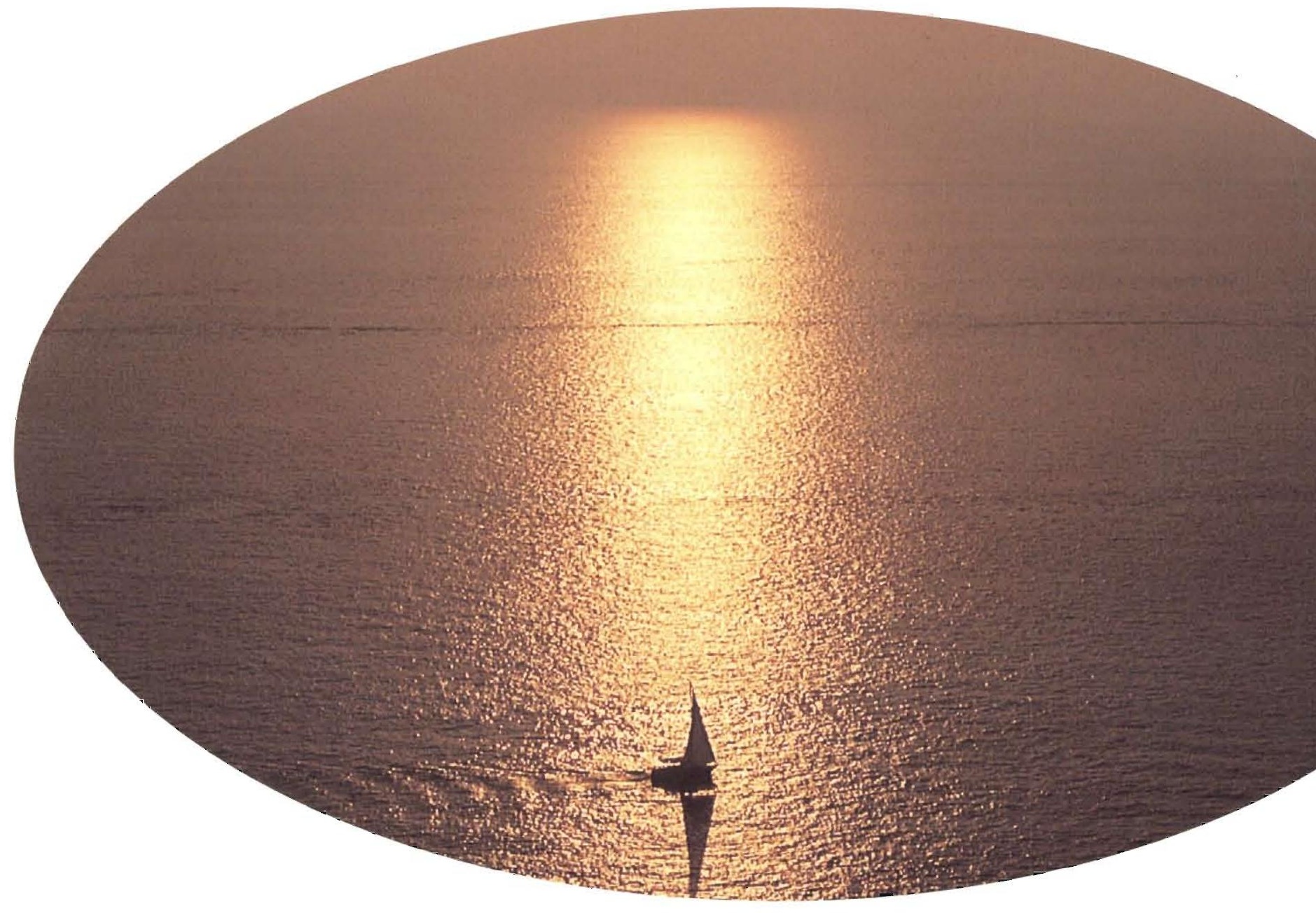

Retrouvez le catalogue en ligne des publications récentes du Service des Editions de l'Ifremer à l'adresse.

Découvrez également un ensemble de documents scientifiques, accessibles gratuitement, dans Archimer. 


\title{
Microalgues marines Les enjeux de la recherche
}

\author{
Arnaud Muller-Feuga
}

Ont participé à la rédaction de cet ouvrage coordonnée par Arnaud Muller-Feuga :

G. Barbier, J.-P. Baud, J.-P. Blancheton, P. Durand, P. Gentien, A. Hervé, J. Hussenot, P. Lassus, J.-L. Nicolas, R. Robert, J. Robin, P. Roy, J.-F. Samain, G. Baudimant (SEAB), J.-P. Bergé (univ. Nantes), B. Berland (univ. Marseille), P. Divanach (IMBC, Grèce), J.-P. Dubacq (ENS UIm), T. Lissolo (univ. Savoie), C. Largeau (ENSCP), J.-M. Robert (univ. Nantes). 


\section{Sommaire}

Introduction

\section{Chapitre I : Thèmes de recherche développés à I'IFREMER}

Le dispositif de recherche et de service

Aspects génériques

La qualité microbiologique des algues

Maîtrise de la production phototrophe

$\begin{array}{lr}\text { Coût de revient des microalgues produites en phototrophie } & 10\end{array}$

Chimie fine

Les stades de développement de la recherche 11

$\begin{array}{ll}\text { Lipides et AGPI } & 11\end{array}$

$\begin{array}{lr}\text { Substances à activités biologiques } & 13\end{array}$

$\begin{array}{lr}\text { Enzymes } & 15\end{array}$

$\begin{array}{lr}\text { Polysaccharides } & 15\end{array}$

$\begin{array}{ll}\text { Aquaculture des mollusques } & 16\end{array}$

Les microalgues fourrage en écloserie-nurserie, un enjeu pour la conchyliculture 16

$\begin{array}{ll}\text { Prégrossissement intensif de coquillages } & 18\end{array}$

$\begin{array}{lr}\text { Télécaptage de l'huître creuse } & 18\end{array}$

$\begin{array}{lr}\text { Affinage de l'huitre creuse } & 18\end{array}$

$\begin{array}{lr}\text { La couleur des huîtres } & 19\end{array}$

$\begin{array}{lr}\text { Environnement } & 19\end{array}$

$\begin{array}{lr}\text { Utilisations potentielles des microalgues toxiques } & 19\end{array}$

Épuration des effluents de l'aquaculture intensive 22

\section{Chapitre II : Autres thèmes}

$\begin{array}{lr}\text { Alimentation } & 25 \\ \text { Homme } & 25 \\ \text { De nouvelles sources d'AGPI à trouver } & 25\end{array}$

Poissons

$\begin{array}{lr}\text { Chimie fine } & 27\end{array}$

$\begin{array}{lr}\text { Antioxydants } & 27\end{array}$

$\begin{array}{lr}\text { Pigments } & 27\end{array}$

$\begin{array}{ll}\text { Marquage moléculaire aux isotopes stables } & 28\end{array}$

$\begin{array}{lr}\text { Environnement } & 28\end{array}$

$\begin{array}{lr}\text { Épuration du } \mathrm{CO}_{2} & 28\end{array}$

$\begin{array}{lr}\text { Support de la vie dans l'espace } & 29\end{array}$

$\begin{array}{ll}\text { Énergie } & 29\end{array}$

$\begin{array}{lr}\text { Hydrocarbures } & 29\end{array}$

$\begin{array}{lr}\text { Production } d \text { 'hydrogène } & 29\end{array}$

$\begin{array}{ll}\text { Conclusions } & 30\end{array}$

Annexe I : Analyse des brevets $\quad 32$

Annexe II : Analyse des publications $\quad 35$ 


\section{Introduction}

Parmi les microorganismes présentant un intérêt industriel, les microalgues, cyanobactéries et bactéries photosynthétiques occupent une place à part dans la mesure où elles ont besoin d'une source de lumière, en plus des conditions générales de culture. Dans le milieu marin, ces organismes constituent le phytoplancton qui est à la base de toute la chaîne alimentaire et supporte une production de ressources renouvelables exploitée de l'ordre de 100 millions de tonnes par an. Par leur taille de l'ordre de quelques $\mu \mathrm{m}$, leur durée de génération de l'ordre de la journée, leur diversité taxonomique (40 000 espèces, dont 100 étudiées et 10 exploitées) et donc biochimique, ils peuvent donner lieu à de nouvelles applications scientifiques et économiques. Leurs particularités biochimiques les plus marquées concernent les lipides, les polysaccharides, les pigments protéiques et caroténoïques, les enzymes et les substances bioactives. Ces molécules intéressent de nombreuses applications dans les domaines de l'alimentation, la santé, la cosmétique, etc. En outre, leur rôle dans l'élevage larvaire de certains animaux marins (mollusques et, dans une moindre mesure, poissons) confère aux microalgues un intérêt stratégique en aquaculture. Enfin, certaines propriétés concernent l'environnement (efflorescences toxiques, mobilisation de nitrates, de $\mathrm{CO}_{2}$ ), la vie dans l'espace, la production d'énergie renouvelable (hydrocarbures, hydrogène, etc.).

La présente étude a pour objet de décrire les enjeux des microalgues et l'état de la recherche les concernant. Sur le plan national, elle est concentrée sur deux groupes du CNRS (URA ENS Ulm, et URA Roscoff). De nombreuses études très ponctuelles ont lieu dans les universités en fonction d'opportunités géographiques et d'intérêts scientifiques locaux. En outre, quelques laboratoires du CNRS ou des grands établissements publics de recherche utilisent des microalgues, mais il s'agit alors d'études portant sur un nombre limité d'espèces prises comme modèle pour un problème biologique, et non pas sur les algues en elles-mêmes. Dans ce contexte, I'IFREMER, organisme de recherche finalisée, a reçu pour mission la valorisation des produits d'origine marine, le soutien aux activités maritimes traditionnelles de pêche, d'aquaculture, et la surveillance de l'environnement côtier. Après une description des travaux en cours dans les directions des Ressources vivantes (chimie fine, technologie des systèmes productifs, aquaculture, microbiologie), et de l'Environnement littoral (microalgues toxiques), ainsi que dans les laboratoires associés à ces travaux (École normale supérieure, universités de Nantes, de Bretagne occidentale, de Villetaneuse...), les enjeux sont évalués pour les différentes applications, en précisant les potentiels de recherche internes et externes. Les thèmes transversaux tels que la caractérisation des souches, les techniques d'obtention d'organismes surproducteurs, et les technologies des systèmes productifs assurant l'accès à la ressource, sont également abordés.

Il faut noter qu'une analyse semblable avait été demandée en 1990 par le ministère chargé de la Recherche et de la Technologie. Elle a permis d'identifier les thématiques stratégiques et de bâtir certains programmes de recherche. Ayant consacré des moyens importants à la recherche appliquée aux microalgues, le Commissariat à l'énergie atomique (CEA) pilotait cette réflexion nationale. À la suite du recentrage de ses activités rendu nécessaire par les redéploiements budgétaires de 1992, et de la cession de sa propriété industrielle à la société Héliosynthèse créée en 1993 (devenue Thallia Pharmaceuticals en 1996), cet organisme a mis un terme à ses activités sur ce sujet. Notre analyse s'appuie sur cette réflexion et sur différents travaux de description de la situation mondiale des activités commerciales liées aux microalgues, en particulier le répertoire $\mathrm{Nec}$ ton de la biotechnologie des microalgues ${ }^{1}$ (1995).

1. Édité par V. Verdelho Vieira et N. Baylina et publiée par l'École supérieure de biotechnologies de I'Université catholique portugaise avec le support financier du programme européen CEDRE-PACTE/PEE. 
Chapitre I

Thèmes de recherche développés à I'IFREMER 


\section{Le dispositif de recherche et de service}

Deux directions opérationnelles de I'IFREMER sont impliquées dans la recherche sur les microalgues, celle des Ressources vivantes (DRV), et celle de l'Environnement littoral (DEL). Le tableau 1 décrit le dispositif de recherche de I'IFREMER en 1996. Les équipements destinés à la production des microalgues pour les besoins divers de la recherche sont très complets, avec notamment 12 salles de culture d'algues. Parmi ces travaux, il convient de distinguer la recherche proprement dite, des services consistant dans la répétition de gestes prédéfinis.

\begin{tabular}{|c|c|c|c|c|}
\hline Département & Laboratoire & Site & Objet & Équipements \\
\hline \multirow[t]{3}{*}{$\begin{array}{l}\text { DRV } \\
\text { Valorisation } \\
\text { des produits }\end{array}$} & \multirow[t]{2}{*}{$\begin{array}{l}\text { biochimie } \\
\text { et molécules } \\
\text { marines }\end{array}$} & Nantes & $\begin{array}{l}\text { extraction et purification } \\
\text { de molécules }\end{array}$ & $\begin{array}{l}\text { salle de culture, } \\
\text { analyse }\end{array}$ \\
\hline & & Brest & génie des procédés de production & photobioréacteur \\
\hline & $\begin{array}{l}\text { caractérisation } \\
\text { microorganismes } \\
\text { marins }\end{array}$ & Brest & $\begin{array}{l}\text { identification et stabilisation } \\
\text { de la qualité des souches }\end{array}$ & microbiologie \\
\hline \multirow[t]{8}{*}{$\begin{array}{l}\text { DRV } \\
\text { Ressources } \\
\text { aquacoles }\end{array}$} & \multirow[t]{2}{*}{$\begin{array}{l}\text { physiologie } \\
\text { des invertébrés }\end{array}$} & Brest & $\begin{array}{l}\text { production et évaluation } \\
\text { pour nutrition des bivalves } \\
\text { et proies vivantes de poissons }\end{array}$ & $\begin{array}{l}\text { salle de culture, } \\
\text { analytique, } \\
\text { biochimie }\end{array}$ \\
\hline & & Argenton & $\begin{array}{l}\text { production pour nutrition } \\
\text { des larves et géniteurs d'huîtres }\end{array}$ & salle de culture \\
\hline & \multirow[t]{2}{*}{$\begin{array}{l}\text { génétique } \\
\text { aquaculture } \\
\text { et pathologie }\end{array}$} & La Tremblade & $\begin{array}{l}\text { production et évaluation } \\
\text { pour nutrition des larves } \\
\text { et géniteurs d'huîtres }\end{array}$ & $\begin{array}{l}\text { microbiologie, } \\
\text { salles de culture (2), } \\
\text { bassins }\end{array}$ \\
\hline & & Bouin & $\begin{array}{l}\text { production sur eaux souterraines, } \\
\text { nutrition des huîtres }\end{array}$ & $\begin{array}{l}\text { salle de culture, } \\
\text { bassins }\end{array}$ \\
\hline & $\begin{array}{l}\text { recherche } \\
\text { aquacole } \\
\text { en Méditerranée }\end{array}$ & Palavas & $\begin{array}{l}\text { production des poissons } \\
\text { et mollusques, } \\
\text { traitement des effluents, }\end{array}$ & $\begin{array}{l}\text { salle de culture, } \\
\text { lagunages }(2+2)\end{array}$ \\
\hline & \multirow[t]{2}{*}{$\begin{array}{l}\text { aquaculture } \\
\text { tropicale }\end{array}$} & Tahiti & $\begin{array}{l}\text { production pour nutrition } \\
\text { des crevettes, et nacre }\end{array}$ & salle de culture \\
\hline & & La Martinique & production de poissons & salle de culture \\
\hline & CREMA & L'Houmeau & $\begin{array}{l}\text { épuration des effluents } \\
\text { de pisciculture intensive }\end{array}$ & $\begin{array}{l}\text { salle de culture, } \\
\text { bacs, bassins, } \\
\text { lagunes }\end{array}$ \\
\hline \multirow[t]{3}{*}{ DEL } & $\begin{array}{l}\text { phycotoxines } \\
\text { et nuisances }\end{array}$ & Nantes & $\begin{array}{l}\text { étude et détection des phyco- } \\
\text { toxines marines }\end{array}$ & $\begin{array}{l}\text { salle de culture, } \\
\text { analyse }\end{array}$ \\
\hline & écologie & Brest & $\begin{array}{l}\text { écologie du plancton nuisible, } \\
\text { déterminisme des événements }\end{array}$ & $\begin{array}{l}\text { salles de culture, } \\
\text { analyse, } \\
\text { prélèvement }\end{array}$ \\
\hline & $\begin{array}{l}\text { RÉPHY (Réseau } \\
\text { phytoplancton) }\end{array}$ & $\begin{array}{l}\text { implantations } \\
\text { nationales }\end{array}$ & $\begin{array}{l}\text { connaissance et identification } \\
\text { du phytoplancton }\end{array}$ & $\begin{array}{l}\text { prélèvement, } \\
\text { identification, ana- } \\
\text { lyse }\end{array}$ \\
\hline
\end{tabular}

Tableau 1 - Le dispositif de recherche et services en rapport avec les microalgues, tel que déployé à l'IFREMER en 1996. 
Au sein de la DRV, les microalgues sont étudiées par le département Valorisation des produits (VP) pour leur capacité à produire des molécules d'intérêt principalement alimentaire et pharmaceutique. Ces études sont conduites dans le cadre du laboratoire Biochimie et molécules marines. Le laboratoire Caractérisation des microorganismes marins, nouvellement constitué, est également impliqué dans le contrôle de la qualité de ces microorganismes pour les différentes applications.

Le département Ressources aquacoles (RA) étudie la nutrition des larves de poissons, mollusques et crustacés. À la base de cette recherche, il assure en routine le service consistant dans la production de microalgues fourrage pour les écloseries expérimentales dans des installations de culture implantées sur huit sites différents.

Au sein de la DEL, les laboratoires Phycotoxines et nuisances (Nantes) et Écologie (Brest) consacrent également une importante charge de travail à l'étude des microalgues toxiques et nuisibles au titre de la mission de surveillance des efflorescences toxiques. Ces activités consistent dans la recherche et dans la surveillance en routine du phytoplancton côtier pour détecter les risques pour la santé humaine et animale (RÉPHY).

\section{Aspects génériques}

\section{La qualité microbiologique des algues}

Les microalgues ont besoin de lumière pour se développer. À cette nuance près, elles sont comme les autres microorganismes : une maîtrise poussée de la microbiologie de ces espèces est une garantie de qualité. Cette maîtrise porte en particulier sur le contrôle des contaminations et I'identité génétique des cultures, pour lesquels des progrès sensibles restent à faire.

Les souches d'algues fourrage sont souvent contaminées par des bactéries, voire d'autres microalgues. Un contrôle de la qualité des souches est donc nécessaire. Les bactéries ne sont pas trop gênantes dans les enceintes de production en batch, car les populations bactériennes restent faibles comparées à celles des algues. Par contre, dans des cultures en continu à forte densité, la moindre contamination initiale aboutit à $d^{\prime} i m$ portants développements qui compromettent rapidement la production algale.

La pratique des cultures en continu comporte donc une exigence de qualité accrue par rapport aux cultures en batch. L'usage des souches axéniques (sans bactérie) devient nécessaire, et requiert une technicité plus grande.

Les méthodes de biologie moléculaire, et notamment le séquençage de I'ARN 16S, permettent I'identification sûre des microorganismes d'une façon générale. Appliquées aux microalgues, elles évitent une confusion entre les souches, aujourd'hui fréquente. Les méthodes de conservation des souches d'algues doivent être améliorées pour limiter les dérives génétiques et éviter la perte des souches d'intérêt.

La cryopréservation est la méthode la plus efficace, et la plupart des espèces marines la supportent après un choix judicieux des agents de préservation et du profil de descente en température. Ces techniques, déjà maîtrisées pour certaines espèces, devront être généralisées. En conclusion, un effort important de rationalisation et une mise à jour des pratiques sont nécessaires à la suite de la réflexion d'ensemble menée sur la qualité microbiologique des algues.

\section{Maîtrise de la production phototrophe}

Les microalgues présentent des temps de doublement sensiblement plus longs que les microorganismes chimio-organotrophes (bactéries, levures et champignons). En effet, il s'agit de $24 \mathrm{~h}$ environ, au lieu de $20 \mathrm{mn}$ à $1 \mathrm{~h}$. En outre, la production de microalgues est basée sur un compromis entre la nécessité de laisser passer la lumière et celle d'atteindre les concentrations élevées facilitant la séparation. Si l'on ajoute que la différence d'un ordre de grandeur entre la productivité des chimioorganotrophes $\left(10 \mathrm{~g} . \mathrm{I}^{-1} . \mathrm{j}^{-1}\right)$ et celle des phototrophes $\left(0,3\right.$ g. $\left.\mathrm{l}^{-1} . \mathrm{j}^{-1}\right)$ est nettement en faveur des 
premiers, on comprend mieux que la production chimio-organotrophe soit moins coûteuse et qu'il faille la choisir chaque fois que cela est possible. Certaines microalgues présentent une aptitude à la chimio-organotrophie (Tetraselmis suecica, Nitzschia, Chryptecodynium). Mais I'absence de lumière réprime la synthèse de certaines molécules (enzymes, lipides, pigments) et restreint la diversité biochimique. Les cultures phototrophes présentent donc un intérêt suffisamment marqué pour justifier un effort de développement de leurs systèmes de production. L'IFREMER, et auparavant le CNEXO (Centre national pour l'exploitation des océans), s'y est employé aux côtés d'autres établissements de recherche (CEA, Intechmer, École centrale de Paris, IUT Saint-Nazaire).

\section{État des lieux}

Lors de la diversification de l'aquaculture marine dans les années soixante-dix, le CNEXO a contribué à perfectionner la production des microalgues en écloserie. Les techniques développées à cette époque ont été largement diffusées en France et ailleurs, et sont encore celles utilisées aujourd'hui. Elles mettent en œuvre des récipients cylindriques à parois en matière plastique transparente souple (gaine de polyéthylène) ou rigide (scobalite), recevant latéralement une lumière le plus souvent artificielle.

Les cultures sont conduites "en batch ", c'est à dire par inoculation d'un milieu stérile suivi d'une récolte totale en fin de croissance exponentielle, soit au bout de quelques jours d'incubation. Les productivités $\left(3 \mathrm{~g} / \mathrm{m}^{2} / \mathrm{j}\right)$ et les concentrations $(0,1 \mathrm{~g} / \mathrm{l})$ restent faibles. Les besoins en investissement et en main d'œuvre sont importants, et le coût de revient varie entre 200 et $1000 \$$ US $/ \mathrm{kg}$ de biomasse sèche ${ }^{2}$ en fonction de la capacité des installations, qui est comprise entre quelques $\mathrm{kg}$ (poids sec) par mois et une tonne par an. Nos calculs montrent (voir la section consacrée aux coûts de revient, infra) que ces chiffres sont sous-estimés.

La recherche des gains de productivité entraîne des besoins nouveaux visant une diminution des coûts, et une maîtrise plus complète de la qualité. Ces besoins sont pris en compte dans deux programmes de recherche de l'IFREMER : les systèmes de production rustiques et peu onéreux basés, par exemple, sur l'utilisation des eaux salées souterraines; les réacteurs de culture en conditions très contrôlées assurant la stabilité qualitative et quantitative, même à des coûts élevés.

\section{Culture sur eau salée souterraine}

Les potentialités industrielles de la production de la diatomée Skeletonema costatum sur eau salée souterraine en bassin à ciel ouvert ont été étudiées pour l'aquaculture et pour la chimie fine. Cette microalgue endémique dominante présente une aptitude particulière à cultiver ce milieu.

La productivité des cultures en "batch " sur trois jours est élevée $\left(16 \mathrm{~g} \cdot \mathrm{m}^{-2} \cdot \mathrm{j}^{-1}\right)$, mais les concentra-

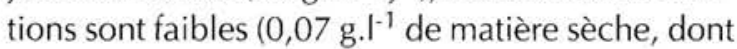
$70 \%$ organique), ce qui nécessite une séparation laborieuse quand il s'agit de récolter la biomasse. En revanche, la main d'œuvre et les autres entrants du coût de revient sont peu onéreux, et la production s'étale sur une partie importante de l'année.

Après avoir cherché à augmenter les rendements et à étendre la culture à d'autres espèces, les limites de cette technologie semblent avoir été atteintes : si les microalgues cultivables se réduisent à une seule espèce, et si des risques de dérapage par contamination existent, pour autant, la simplicité et la robustesse de ce système de production se révèlent une opportunité réelle dans les zones humides littorales présentant des ressources en eaux salées souterraines, lesquelles couvrent une partie importante du domaine conchylicole français. Cette technique a donné lieu à des développements décrits plus loin (voir "Prégrossissement d'huîtres creuses infra »).

\section{Photobioréacteur solaire}

Dans le cadre d'une collaboration avec le CEA de 1990 à 1993, une technologie de réacteur solaire parmi les plus en pointe a été maîtrisée et enrichie. En particulier, les travaux ont porté sur l'utilisation des panneaux alvéolaires en polymétacrylate extrudé, et les systèmes de nettoyage de la paroi interne du réacteur. Par la suite, ces acquis technologiques ont été transférés par le CEA à la société Thallia Pharmaceuticals, qui devrait les mettre en œuvre dans le cadre d'un projet industriel de photobioréacteur tubulaire de $1000 \mathrm{~m}^{2}$ destiné à la production de Porphyridium cruentum pour ses lipides et sa superoxyde dismutase

2. J.-R. Benemann, Microalgae aquaculture feeds, J. App. Phycol., 1992. 
(SOD). Les productivités maximales en continu pour cette espèce atteignent $7 \mathrm{~g} . \mathrm{j}^{-1}$ par $\mathrm{m}^{2}$ de surface développée (ou $20 \mathrm{~g}^{-j^{-1}}$ par $\mathrm{m}^{2}$ de surface

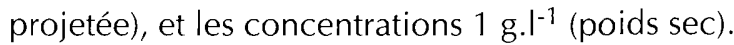
Dans le domaine public depuis $1983^{3}$, cette technologie est également mise en œuvre par l'université Ben-Gourion du désert (Israël), et l'université d'Almeria (Espagne), pour la recherche.

\section{Développements en cours}

\section{Photobioréacteur en lumière artificielle}

À la suite de la cession du savoir-faire à sa filiale Thallia Pharmaceuticals, le CEA a cessé toute activité de recherche dans le domaine en 1992. L'IFREMER reste donc le seul établissement de recherche public français (hors universités) à poursuivre des travaux dans le domaine du génie des procédés de production de microalgues. Un programme cofinancé par la région des Pays de Loire porte notamment sur le développement d'un photobioréacteur à usage préparatif pour la production de molécules à haute valeur ajoutée et pour l'aquaculture. Les paramètres majeurs de la culture en continu (turbidité, température, $\mathrm{pH}$, oxygène dissous, pression, lumière) sont stabilisés par des régulations indépendantes. Le milieu réactionnel circule en boucle dans une série de chambres lumineuses équipées chacune d'une lampe fluorescente. Ce concept, dit LAMP pour "Lumière Artificielle, Moyenne Productivité ", prévoit un assemblage des chambres en nombre variable qui permet une adaptation de la taille du réacteur aux différents besoins. Un contrôle poussé des flux entrant et sortant permet d'établir des bilans liquides et gazeux.

L'exploitation du prototype en matière plastique (LAMP $1: 0,8 \mathrm{~m}^{2}, 28$ l, épaisseurs 30 et $8,5 \mathrm{~mm}$ ) est en cours à Nantes. Les productivités pour $P$. cruentum atteignent $15 \mathrm{~g} / \mathrm{j}$ par $\mathrm{m}^{2}$ de surface développée, et les concentrations $1 \mathrm{~g} / \mathrm{l}$. Après des études s'appuyant notamment sur les résultats de LAMP 1, un démonstrateur en inox et verre (LAMP $2: 1,5 \mathrm{~m}^{2}, 100 \mathrm{l}$, épaisseur $30 \mathrm{~mm}$ ) est en cours d'évaluation. Il présente des fonctionnalités nouvelles parmi lesquelles le réglage de l'intensité lumineuse et la possibilité de stériliser à la vapeur. Le développement de ce réacteur original sera suivi, courant 1997, de celui des techniques de récolte avec séparation de la biomasse et recy- clage des solutions nutritives, selon un mode de fonctionnement en continu. Lors du premier essai avec $P$. cruentum, le réacteur a produit $23 \mathrm{~g} / \mathrm{m}^{2} / \mathrm{j}$ selon une concentration de $1,7 \mathrm{~g} / \mathrm{l}$ pendant 250 heures, montrant un accroissement sensible des performances. Outre la couverture des besoins de la recherche en chimie préparative et en aquaculture, ce type d'équipement pourrait également intéresser certaines PME.

\section{Recherche amont en génie des procédés de production}

Une action visant à optimiser les échanges photoniques dans les chambres à lumière du photobioréacteur LAMP a été formalisée dans le cadre du GIS Progebio, groupement d'intérêt scientifique rassemblant des organismes de recherche impliqués dans le génie des procédés. Elle consiste dans l'étude par modélisation physique et numérique des vitesses transversales à la paroi optique.

Des solutions autres que la turbulence sont recherchées pour renouveler les microorganismes au droit de la paroi lumineuse. C'est ainsi que l'on évaluera les écoulements tourbillonnaires induits par la force centrifuge de type Dean, et CouetteTaylor qui se forment en régime laminaire (à faible vitesse). La diminution des sollicitations mécaniques peut améliorer la culture des microalgues fragiles (flagellées, à appendices) et rendre possible celle d'autres particulièrement sensibles (dinoflagellés).

\section{Coût de revient des microalgues produites en phototrophie}

À $300 \mathrm{~F} / \mathrm{kg}$, la biomasse cultivée sur eau salée souterraine est de loin la moins chère. Pour autant, l'exploitation de cet avantage est limité par la difficulté de cultiver d'autres espèces que $S$. costatum, et par le fait que le vieillissement de ces eaux, dont les gisements sont localisés, leur fait perdre rapidement toute valeur nutritive. Viennent ensuite les réacteurs solaires de grande taille (4 $000 \mathrm{~F} / \mathrm{kg}$ ), puis en lumière artificielle de taille préparative (8 $000 \mathrm{~F} / \mathrm{kg})$, et enfin les salles d'algues conventionnelles (plus de $10000 \mathrm{~F} / \mathrm{kg}$ ). La main $d^{\prime} œ u v r e$ est le poste principal dans le cas des salles d'algues, à la différence des photobioréacteurs. La part du coût du milieu de culture est

3. Brevet Grande Bretagne de S.J. Pirt, univ. Londres, non étendu en France. 
significative (de 10 à $50 \%$ ), et ce constat parle en faveur du recyclage des solutions nutritives après séparation de la biomasse, dans le cas où celle-ci est nécessaire, c'est à dire pour les applications autres que l'aquaculture (chimie fine). On constate que l'énergie électrique ne représente pas un poste important (quelques \%) dans le cas des photobioréacteurs en lumière artificielle.

Les avantages des photobioréacteurs sont donc de nature non seulement qualitative (stabilité bactériologique et biochimique), mais également éco- nomique (coût de revient 30 à $60 \%$ plus faible que celui des salles d'algues), et justifient la conduite d'un effort de recherche dans une perspective de soutien au développement industriel. Le coût de l'énergie de la lumière artificielle n'apparaît pas de nature à constituer un handicap. En permettant d'abolir les nuits, les saisons, les passages nuageux et l'effet des hautes latitudes sur I'ensoleillement, et donc de produire toute I'année dans des conditions parfaitement stabilisées, cette solution est adaptée aux productions préparatives de haute qualité.

\section{Chimie fine}

\section{Les stades de développement de la recherche}

L'intérêt scientifique et économique des molécules de microalgues par rapport aux autres sources ont justifié un certain nombre d'actions qui sont décrites ici. Avant de les passer en revue, il paraît utile de rappeler comment obtenir ces molécules en plus grande quantité, et diminuer ainsi les coûts de production. Selon la molécule ciblée, il faut en effet choisir une souche productrice, et un état physiologique (ou une procédure) permettant d'accroître le rendement. Après avoir déterminé avec précision la (ou les) molécule(s) intéressante(s) et les critères analytiques appropriés, les étapes successives consistent à :

- 1. Choisir des espèces favorables à partir des données de la littérature, vérifier leurs performances, et sélectionner les souches les plus productrices ; - II. Déterminer les conditions les plus favorables à la production de la molécule ciblée, et réaliser ces conditions à l'aide d'une technologie appropriée ;

- III. Manipuler génétiquement les souches sélectionnées pour accroître encore leur production de molécule,

- par croisement direct si les formes sexuées sont disponibles,

- par cycle de mutation/sélection,

- par mutation dirigée, si la connaissance complète du contrôle génomique du métabolisme est disponible ;

- IV. Transférer, dans le cas des protéines, leurs séquences de gènes chez des bactéries connues en vue d'une production recombinante en fermentation traditionnelle.

Pour la plupart des molécules de microalgues actuellement ciblées à l'IFREMER, les stades I et II sont en cours. Le stade III est abordé dans le cadre d'une collaboration avec l'École normale supérieure et I'université d'Almeria pour les lipides. Le stade IV ne concerne que les protéines et n'a pas encore démarré. Cette situation, qui reflète celle de la plupart des acteurs scientifiques et industriels de la filière des microalgues dans le monde, doit probablement durer encore assez longtemps.

La production en chimio-organotrophie n'étant pas une solution applicable à toutes les microalgues d'intérêt, on constate que la maîtrise de l'accès à la ressource nécessaire à tout développement industriel passe par le développement de systèmes de production photoautotrophe performants. Ce besoin est renforcé par la nécessaire conformité à des standards de plus en plus rigoureux en matière de qualité (Bonnes pratiques de laboratoire, BPL ; normes ISO...).

\section{Lipides et AGPI}

La diversité des critères utilisés pour caractériser les lipides (propriétés physiques, structures chimiques, fonctions biologiques) ne permet pas de dégager une classification homogène et universellement admise par l'ensemble des équipes travaillant dans ce domaine. Cependant, la distinction des classes de lipides en lipides neutres, 
glycolipides et phospholipides semble obtenir un large consensus de la part des lipochimistes.

\section{Les lipides neutres}

Au sein des lipides neutres, les triglycérides et les acides gras libres (sous forme d'esters ou non) sont de loin les plus exploités essentiellement pour des applications alimentaires, cosmétiques et pharmaceutiques. Les huiles de poissons constituent une des principales sources de ces composés. Elles ne représentent cependant qu'approximativement $2 \%$ en tonnage de la production annuelle des huiles et des graisses, et proviennent principalement d'espèces comme le hareng, la sardine, I'anchois, la morue, le menhaden et le capelan. Leur principale application (environ $70 \%$ ) est la production de margarine ; les $30 \%$ restant sont utilisés en alimentation animale ou dans des produits cosmétiques, pharmaceutiques ou diététiques.

La caractéristique principale et valorisante des lipides neutres issus des huiles de poissons est la présence d'acides gras polyinsaturés à longue chaîne (AGPI) de la série $\omega 3$ de type EPA (20:5 $\omega 3$ ) et DHA (22:6 $\omega 3)$ en quantité abondante selon les espèces exploitées.

Une huile de sardines classique commercialisée au prix moyen de $25 \mathrm{~F} / \mathrm{I}$ renferme un mélange de triglycérides riches en EPA/DHA représentant respectivement 18 et $12 \%$ des acides gras totaux. Cette production d'huile riche en AGPI de la série $\omega 3$ est une caractéristique que ne possède pas I'autre source primaire majeure que constituent les végétaux supérieurs qui, eux, ont développé la série $\omega 6$, et qui produisent notamment I'acide arachidonique (20:4 $\omega 6$ ou AA).

Des données récentes ${ }^{4}$ font mention d'un besoin mondial de 100 t/an pour l'AA, 40 t/an pour l'EPA et 27 t/an pour le DHA. Le marché potentiel des AGPI, principalement destinés aux industries alimentaires et laitières (AA et DHA), est estimé à 900 millions de \$ US en 1995. L'EPA est proposé par Pharmaglobe Laboratories (Ontario, Canada) au prix de 10000 \$ US/kg pour une pureté de $98 \%$. Le marché est estimé ${ }^{5}$ entre 50 et 80 millions de \$ US, en augmentation de $10 \%$ par an.
Les lipides neutres des microalgues partagent avec les huiles de poissons la présence d'AGPI de la série $\omega 3$ de type EPA et DHA, mais s'en distinguent soit par une composition monospécifique en ces acides gras à longue chaîne, soit par la présence de composés appartenant à d'autres familles, notamment de la série $\omega 6$, comme I'AA trouvé chez la microalgue rouge $P$. cruentum. Les huiles issues de microalgues ne sont pas dépourvues d'intérêt commercial en raison de l'importante diversité de leurs AGPI et, à l'instar d'autres sources, de propriétés intéressantes telles que d'être moins odorantes et plus pauvres en cholestérol. Les microorganismes chimio-organotrophes (bactéries, champignons, microalgues) produisent I'AA et le DHA dans des conditions de rentabilité meilleures que les microalgues photolithotrophes. La spécificité de ces dernières s'exerce plutôt pour I'EPA que seuls produisent des vibrions suspects de toxicité. Dans ce contexte, les diatomées $P$. tricornutum ou $S$. costatum sont des candidats intéressants, la première en photobioréacteurs, la seconde en bassins ouverts sur eau salée souterraine. Bien qu'il soit à ce jour difficile d'envisager une taille de marché et un prix de vente pour ces produits nouveaux, certaines sociétés investissent dans cette voie. Nous mentionnerons notamment Kelco et Martek aux USA (chimio-organotrophie), Thallia Pharmaceuticals en France (chimio-organotrophie et photo-lithotrophie), Inalco en Italie (photo-lithotrophie), dont les programmes ne sont pas connus avec précision.

\section{Les glycolipides}

Outre les lipides neutres, les glycolipides constituent une opportunité intéressante de valorisation des microalgues. En effet, les glycolipides végétaux sont impliqués dans le processus photosynthétique et, à ce titre, se distinguent, par leur nature, des glycolipides animaux ou d'organismes chimio-organotrophes.

En outre, la présence d'acides gras polyinsaturés à longues chaînes estérifiés au radical sucre confère aux microalgues une spécificité forte. Deux marchés peuvent être envisagés pour ces composés. L'absence de certains glycolipides dans le domaine des réactifs biochimiques conjuguée à une demande croissante de ces composés, en 
particulier du sulfoquinovosyldiacylglycérol (SQDG), peut représenter une voie de valorisation à court ou moyen terme.

Par ailleurs, le SQDG suscite un vif intérêt en recherche médicale, soutenue par l'industrie pharmaceutique, dans la mesure où des propriétés prometteuses ont été mises en évidence lors d'une recherche antiVIH au NIH. Cet axe de valorisation à plus long terme n'est donc pas à exclure et peut constituer dans l'immédiat une ouverture de la recherche et des collaborations scientifiques.

\section{Les phospholipides}

Ce sont des composés présents dans tous les organismes où ils participent à des fonctions cellulaires diverses. Ces lipides font aujourd'hui l'objet d'une commercialisation importante notamment sous l'appellation lécithine qui est un terme générique désignant un mélange de phospholipides à degré de pureté variable. Les applications industrielles des lécithines sont diverses et à considérer sous l'angle de la ressource. En effet, les lécithines sont très utilisées en industrie alimentaire en qualité d'auxiliaire technologique, et le soja est l'une des rares sources qui ne nécessite pas de caractéristiques lipochimiques particulières, hormis le degré de pureté. La demande des industries pharmaceutiques et cosmétiques diffère de la précédente de par les applications des phospholipides.

En effet leur double polarité (hydrophile et hydrophobe) leur confère la propriété d'être de bons vecteurs d'acides gras ou de principes actifs (liposomes, nanoémulsions). Les AGPI estérifiés à ces phospholipides confèrent aux microalgues une spécificité intéressante et prometteuse au regard d'autres sources. En effet, les phospholipides (notamment la phosphatidylcholine) à estérification en AGPI de type acide AA ou DHA proviennent principalement de sources animales (cerveau de bovins, foie de porc, extrait placentaire) qui sont rejetés en raison des risques liés aux protéines protéase résistantes (EBS, Creutzfeld-Jacob).

La recherche, très active à ce jour, de ressources substitutives à ces produits animaux permet d'envisager une exploitation des phospholipides issus de certaines espèces de microalgues. À titre indicatif, la phosphatidylcholine estérifiée par l'acide palmitique (16:0) et l'AA (20:4 $\omega 6)$, à $98 \%$ de pureté, coûte $1448 \mathrm{FF}$ pour $100 \mathrm{mg}$ au catalogue
Sigma de 1997. On trouve environ $1 \%$ de cette molécule dans $P$. cruentum, ce qui, pour un coût initial de la biomasse sèche de $5000 \mathrm{~F} / \mathrm{kg}$, place le coût de revient de la molécule avant extractionpurification à $50 \mathrm{FF}$ pour $100 \mathrm{mg}$. Cette marge est confortable, mais ne peut générer d'activité commerciale que si le marché est porteur, ce qu'il est difficile de dire à ce stade.

En conclusion, il apparaît que les microalgues peuvent constituer une source intéressante de lipides complexes et originaux. Les marchés de ces composés sont sûrement plus limités que ceux des grands composants alimentaires, et concernent davantage les réactifs biochimiques pour la recherche. Mais ils génèrent des valeurs ajoutées telles que l'on peut s'accommoder de coûts élevés d'accès à la ressource, ce qui est le cas de ces microorganismes. Une approche économique de quelques molécules issues d'espèces couramment exploitées est en cours pour confirmer leur intérêt commercial.

\section{Substances à activités biologiques}

Dans le domaine marin, les substances nouvelles ayant une activité biologique potentiellement intéressante seraient au moins 100 fois plus nombreuses que celle des organismes terrestres. Ainsi, plus de 6000 nouveaux métabolites marins ont été identifiés à ce jour. L'étude systématique des extraits algaux, pour la recherche d'une activité biologique, a commencé dans les années cinquante avec la détection de produits antibiotiques. À l'occasion des premiers criblages à grande échelle menés sur les algues, notamment par l'Institut de recherche Roche en pharmacologie marine, de nombreuses activités biologiques intéressantes ont été découvertes et surtout de nouvelles méthodes de criblage avec des biosuivis d'activités ont permis l'orientation des extractions et purifications.

Depuis, en s'inspirant de ces méthodes, plusieurs centaines de millions de dollars ont été investis dans la recherche de produits nouveaux extraits d'algues, par des sociétés telles que Sea Pharm (États-Unis), Microbio Resources Inc. (États-Unis) et Kirin Brewery (Japon). Ces investissements ont mis en évidence de très nombreuses molécules biologiquement actives présentant une structure nouvelle. Certaines microalgues présentent 
l'avantage par rapport aux macroalgues de pouvoir être aisément cultivées en masse et peuvent donc devenir des sources potentielles de molécules difficilement accessibles par synthèse chimique. Nous ne relaterons ici que les propriétés antivirales, antibiotiques et antiprolifératrices identifiées chez les microalgues en omettant la classe des Dinophyceae qui, à elle seule, a fait I'objet de très nombreux travaux (voir chapitre " environnement » infra).

\section{Activité antivirale}

L'activité antivirale des microalgues n'a été que très peu étudiée in vitro. Les travaux récents sur le virus de l'immunodéficience humaine ont révélé quelques principes actifs principalement chez les cyanophycées, classe des cyanobactéries très étudiée. Une étude portant sur plus de 900 souches, révèle que près de $2 \%$ des extraits aqueux inhibent à plus de $50 \%$ la transcriptase reverse du virus de la myéloblastose aviaire; à l'inverse, les extraits lipophiles de ces mêmes algues ne présentent aucune activité. Dans les autres classes d'algues, un gallotanin de structure non déterminée, possédant une activité antivirale, a été isolé chez une chlorophycée du genre Spirogyra.

\section{Activité antibiotique}

Les microalgues marines ou d'eau douce ont été très largement étudiées pour la recherche de principes actifs antimicrobiens (antibiotique, antifongique, antiviral, anti-algal, protisticide). Un très grand nombre d'extraits algaux ainsi que des produits exocellulaires se sont révélés actifs et il est difficile d'en faire une liste exhaustive. Les substances actives ont cependant été très rarement isolées et identifiées.

Des activités de type antibiotique ont été décrites chez toutes les classes de microalgues, ces activités étant présentes aussi bien dans des extraits aqueux qu'organiques. La majorité des tests d'activité ont été effectués in vitro. Les applications médicinales potentielles apparaissent cependant réduites, au vu de la toxicité ou de l'inactivité des produits révélées par les tests in vivo. Toutefois, ces composés peuvent servir de modèles moléculaires pour la recherche de nouveaux principes actifs. Ainsi, des molécules isolées à partir de microalgues, lors d'un criblage antibiotique, se sont révélées également algicides (ex : haploindole A et cyanobactérine). L'extraction, la purification et la caractérisation d'un principe antibiotique de nature lipidique issu de la diatomée Skeletonema costatum ont été réalisées ${ }^{6}$. Cette activité est intéressante car elle apparaît relativement spécifique des pathogènes aquacoles marins.

\section{Cytotoxicité et activité antiprolifératrice}

La recherche d'activités cytotoxiques et antitumorales a concerné principalement les cyanobactéries. C'est d'ailleurs au sein de cette classe taxonomique que les résultats sont les plus prometteurs (si on excepte celle des dinoflagellés), car si le taux de découverte de molécules actives est identique à celui trouvé dans des sources plus traditionnelles (plantes, champignons...), la redécouverte de molécules déjà connues (qui peut atteindre $95 \%$ chez les actinomycètes par exemple) est ici beaucoup plus faible. Ainsi une étude sur près de 1000 souches de cyanobactéries révèle une activité in vitro pour près de $12 \%$ des extraits testés. Si parmi les différentes molécules isolées certaines s'avèrent être des outils pharmacologiques intéressants, aucune ne fait actuellement l'objet d'utilisation thérapeutique.

On pensait que la classe des diatomées ne produisait pas de toxines jusqu'à ce que l'on découvre de l'acide domoïque chez plusieurs espèces. Elles développent, en outre, des mécanismes de défense comme, par exemple, la synthèse $d^{\prime}$ inhibiteurs de croissance du zooplancton, de médiateurs chimiques régulant le développement d'autres espèces phytoplanctoniques $^{7}$, etc. Récemment la présence d'inhibiteurs du développement des copépodes, qui sont leur principaux "brouteurs", a été démontrée chez plusieurs diatomées. Ces molécules agissent en modifiant le cycle mitotique et l'embryogenèse des œufs d'oursins. De tels agents " antimitotiques ", par leur action sur le cycle cellulaire, peuvent s'avérer être des molécules cytotoxiques ou antitumorales potentielles. Ainsi, une activité antiprolifératrice in vitro a été démontrée chez la diatomée Skeletonema costatum. Le principe actif isolé induit une différenciation terminale atypique des cellules tumorales. C'est ce genre d'activité qui est actuellement recherché pour les chimiothérapies. 


\section{Enzymes}

Depuis 1990, on recense environ 125 articles publiés présentant des études d'activités enzymatiques de microalgues, essentiellement dans les domaines de la physiologie et de la biochimie comparées (annexe II). Comparativement, la recherche d'enzymes de microalgues avec un but de valorisation est quasi absente de la littérature, ce qui implique une première étape d'identification des débouchés éventuels pour ces biocatalyseurs.

Les enzymes de faible valeur utilisées en grande quantité, comme celles destinées aux besoins de I'agro-alimentaire ou des détergents, ne présentent pas d'opportunités sérieuses pour la valorisation des microalgues. Par contre, dans le domaine des applications biomédicales ou analytiques, les perspectives de croissance très prometteuses ainsi que le prix élevé des enzymes permettent d'envisager des développements à court terme. Les enzymes à activité anti-radicalaire, de la famille des superoxydes dismutases (SOD), présentent un intérêt pour le traitement de pathologies chroniques s'accompagnant d'une augmentation du taux de radicaux libres et de formes actives de l'oxygène (voir " antioxydants", infra), telles que le SIDA, certaines formes de cancers, etc..$^{8,9,10}$. L'actualité récente du développement en France d'un site de production de SOD à partir de la microalgue $P$. cruentum illustre les potentialités de valorisation de ce type de recherche pour les microalgues (sociétés Thallia et Scotia Pharmaceuticals). Les activités antiradicalaires d'origine microalgale peuvent, par ailleurs, entrer dans la formulation de soins cosmétiques (complexes anti-âge).

Le domaine des lipides bénéficie actuellement, pour des raisons de santé publique essentiellement, d'un important effort de recherche (voir " lipides ", supra). Ces études nécessitent simultanément un important effort de caractérisation de lipases et d'élongases de microalgues, afin de disposer des outils analytiques mais aussi des biocatalyseurs indispensables à l'analyse et à la synthèse des lipides complexes de ces organismes. À notre connaissance, à ce jour, aucune lipase de microalgue n'a été purifiée. Des travaux récents de I'IFREMER ont cependant montré la présence $d^{\prime}$ activité lipase ${ }^{6}$, probablement glycolipase, dans la microalgue Skeletonema costatum.

Enfin, un domaine plus prospectif mais prometteur consiste en la caractérisation d'enzymes psychrophiles et/ou halophiles, permettant la mise en œuvre de biocatalyses dans des milieux où les enzymes commerciales ne possèdent que de faibles stabilités ou activités. À ce titre, la collecte, la culture et l'étude des souches vivant dans des biotopes spécifiques permettent de fournir la biomasse nécessaire à la caractérisation de ces nouveaux biocatalyseurs.

Le choix de la production d'enzymes par voie extractive à partir de microalgues, ou sous forme de protéines recombinantes sera lié d'une part au développement des capacités de production des microalgues (photobioréacteur), et d'autre part, à la réussite du clonage. En effet, de nombreux problèmes peuvent être rencontrés lors de l'introduction du gène d'une enzyme dans un organisme (levure, bactérie). Ils sont tels que la culture contrôlée de microalgues en photobioréacteur pour l'obtention d'enzymes spécifiques pourrait constituer une solution compétitive vis à vis de la production par voie recombinante.

\section{Polysaccharides}

En dehors des polysaccharides structuraux, certaines microalgues synthétisent des exopolysaccharides. Ces composés hydrophiles et polyanioniques forment une gangue, retiennent l'eau et piègent les cations permettant ainsi à la microalgue de résister à la dessiccation. Ces propriétés de concentration ont suggéré des applications biotechnologiques dans le domaine de l'environnement via la détoxication de milieux pollués par les métaux lourds ( $\mathrm{Pb}, \mathrm{As}, \mathrm{Hg}, \mathrm{Cd}$.) et dans le domaine de la biorécupération de métaux : or, uranium ${ }^{11}$. Les caractéristiques physico-chimiques de ces polymères, notamment leurs propriétés viscosantes, lubrifiantes et floculantes, ont été mises en avant pour des applications variées, telles : récupération assistée du 
pétrole, agent antifriction en mécanique, clarification de l'eau ${ }^{12}$.

En terme de développement, les avantages des microorganismes sur les macroalgues et plantes supérieures sont liés à leur cycle de reproduction très court (de quelques heures au lieu de quelques mois) et à la possibilité de production de polysaccharides en conditions contrôlées par des microorganismes sélectionnés. Mais cette biotechnologie se heurte aux difficultés de production en masse à un coût économique.

12. Borowitzka, M.A., Microbiol. Sci. vol 3, n²12, 1986.

13 Flandry L., Biofutur 159, Sept. 1996.

\section{Aquaculture des mollusques}

\section{Les microalgues fourrage en écloserie-nurserie, un enjeu pour la conchyliculture}

Dès les années trente, il a été démontré que certains flagellés unicellulaires peuvent servir de nourriture à des larves de bivalves. Aujourd'hui, l'apport de microalgues, isolées du plancton marin et mises en culture contrôlée, constitue l'aliment le plus courant pour les bivalves en élevage à tous les stades de développement. Mises au point dans les années soixante, ces productions phytoplanctoniques restent encore la seule technique de production appliquée à ce jour.

Bien que de nouvelles voies aient été prospectées (levures, bactéries, microcapsules, pâtes d'algues ou microalgues séchées ou congelées), aucune d'entre elles n'est actuellement suffisamment avancée pour constituer une solution alternative aux microalgues vivantes. En effet, les nouvelles préparations sont souvent carencées, lorsqu'elles ne constituent pas un substrat de développement bactérien néfaste, surtout pour les stades précoces.

\section{Usage des microalgues dans le système écloserie-nurserie}

Les besoins de phytoplancton sont très différents selon que I'on s'adresse à l'étape du condition-
Par ailleurs la connaissance de la nature biochimique précise de ces polymères apparaît très incomplète. L'émergence de la glycobiologie et les potentialités de développement de biopolymères dans le secteur biologique et médical pourraient générer des études visant à contribuer à la caractérisation et à l'établissement des relations structures-fonctions des polysaccharides de microorganismes marins, notamment de ceux issus des microalgues ${ }^{13}$.

nement des géniteurs, à l'élevage larvaire ou à l'élevage post-larvaire :

- les stades larvaires sont exigeants en qualité microbiologique et nutritionnelle des microalgues, mais peu consommateurs ;

- les stades post-larvaires semblent moins exigeants en qualité microbiologique, mais restent sensibles au nécessaire équilibre en molécules essentielles. Par contre les quantités ingérées sont importantes et proportionnelles au nombre et à la taille des post-larves en élevage ;

- le conditionnement des géniteurs est exigeant en qualité nutritionnelle et en quantité par individu, mais généralement, le nombre d'animaux en conditionnement reste relativement limité.

Bien que globalement maîtrisée, la production en masse de microalgues vivantes en écloserie-nurserie présente donc des contraintes quantitatives et qualitatives importantes (tabl. 2).

Plusieurs lots sont réalisés dans l'année, une écloserie industrielle fonctionnant environ 8 à 10 mois par an. Passée la taille de $3 \mathrm{~mm}$, les animaux sont généralement transférés en milieu naturel ou prégrossis en nourricerie extérieure. Dans de telles structures, les consommations quotidiennes sont encore plus élevées, 40 à $100 \mathrm{~m}^{3}$ de culture extensive (densité moyenne ou équivalent à $10^{6}$ cellules/ml) par million de juvéniles (6 à 12 mm). 


\begin{tabular}{|c|c|c|c|}
\hline Algues à $6.10^{6} \mathrm{cell} / \mathrm{ml}$ & 1 géniteur & $10^{6}$ larves & $\begin{array}{c}10^{6} \text { post-larves } \\
0,2-3,0 \mathrm{~mm}\end{array}$ \\
\hline $\begin{array}{l}\text { Consommation journalière } \\
\text { Mélange plurispécifique } \\
\text { Qualité microbiologique } \\
\text { Durée de l'étape }\end{array}$ & $\begin{array}{c}0,5 \text { à } 2 \text { litres/jour } \\
++ \\
+ \\
1 \text { à } 3 \text { mois }\end{array}$ & $\begin{array}{c}15 \text { à } 20 \text { litres/jour } \\
+++ \\
+++ \\
0,5 \text { à } 1 \text { mois }\end{array}$ & $\begin{array}{c}1000 \text { à } 1500 \mathrm{l} / \text { jour } \\
+ \\
++ \\
2 \text { à } 3 \text { mois }\end{array}$ \\
\hline
\end{tabular}

Tableau 2 - Besoins nutritionnels des huîtres aux différents stades.

\section{Les besoins quantitatifs des écloseries industrielles}

À titre d'exemple, les besoins en culture intensive de l'écloserie de la Coast Seafoods Company, principale écloserie américaine de la côte ouest des États-Unis (20 milliards de larves œillées par an, correspondant à $40000 \mathrm{t}$ d'huîtres commercialisables) sont de $100 \mathrm{~m}^{3} / \mathrm{j}$ à $4.10^{6} \mathrm{cell} / \mathrm{ml}$ (soit environ $4 \mathrm{~kg} / \mathrm{j}$, poids sec). La France produit $130000 \mathrm{t}$ de Crassostrea gigas et a produit, avant l'épizootie des années soixante-dix, 30000 t d'huître plate Ostrea edulis. La production théorique de postlarves équivaudrait à quatre fois celle de la Coast Seafoods Company, si l'on considère que le système de production passe intégralement par l'écloserie.

\section{Évaluation des besoins qualitatifs}

La seconde contrainte est qualitative, tant aux niveaux biochimique que bactérien.

- Au niveau biochimique, il a été montré que la qualité de la reproduction et du développement larvaire et postlarvaire est fortement corrélée à I'utilisation de régimes plurispécifiques, comparés à des régimes monospécifiques.

Ceci résulte des carences induites lors de l'utilisation de régimes monospécifiques, par la composition très caractéristique de chaque espèce de phytoplancton, en particulier en acides gras polyinsaturés (acide gras à 20 et 22 atomes de carbone et à plus de 3 doubles liaisons), ou de leur composition en stérols et à un moindre degré, en vitamines. Par ailleurs, on sait que la composition biochimique des microalgues varie en fonction du milieu de culture choisi, de l'âge et des paramètres physiques de la culture (température, énergie lumineuse, taux de $\mathrm{CO}^{2} \ldots$ ). Or dans la culture en "batch ", la qualité des algues évolue et la stabilité biochimique de la nourriture apportée n'est pas garantie.
- Au niveau bactérien, la charge augmente avec l'âge des cultures qui ne sont que très rarement axéniques à l'origine. Les conditions d'asepsie permettant d'éviter les contaminations secondaires sont rarement respectées pour des volưmes supérieurs à quelques centaines de litres, car ils sont généralement ouverts.

\section{Les techniques de production aujourd'hui}

La culture en "batch " dans des récipients à parois verticales transparentes permet de produire les quantités nécessaires, mais pour un coût élevé (30 à $40 \%$ des charges d'une écloserie, dont plus de $50 \%$ correspond à la seule main d'œuvre), et avec une qualité variable.

\section{Et demain?}

- Pour la conchyliculture et plus spécifiquement pour l'écloserie, l'abandon de la production de microalgues en "batch " au profit d'une production dans des conditions technologiquement, physiologiquement et génétiquement stabilisées, est une des améliorations potentielles. Celle-ci devrait se traduire par des gains substantiels en terme de coût, par la réduction du temps consacré à la culture du phytoplancton, et en terme de qualité de la biomasse (composition plus constante et contamination bactérienne limitée), seule garante d'une bonne production de larves et juvéniles.

- Un autre développement espéré, serait la possibilité de produire les algues dans une unité spécialisée, pour toutes les écloseries-nurseries. C'est d'ores et déjà possible pour les juvéniles et les géniteurs, et cela pourrait le devenir à terme pour les larves à condition que l'on maîtrise la technologie de production, de conservation et d'utilisation des algues préservées. Cette question a fait l'objet du programme européen MANTA ${ }^{14}$, à l'occasion 
duquel les difficultés de cette forme de nutrition larvaire ont été mises en évidence : sur 19 essais d'alimentation à partir de pâte monospécifique $d^{\prime}$ algue produite à distance, un seul a permis d'obtenir des métamorphoses. Cela a montré que I'alimentation inerte n'est pas pour une échéance prévisible, et qu'un perfectionnement de l'alimentation à base $d^{\prime}$ algue est nécessaire économiquement, pour réduire les coûts et améliorer la qualité, et scientifiquement, pour mieux comprendre la nature des besoins.

\section{Les enjeux économiques et sociaux}

La principale menace pour la conchyliculture est une épizootie qui décimerait l'activité très brutalement, comme cela s'est produit pour l'huître portugaise et l'huître plate. L'obtention de souches résistantes aux maladies par la voie de la génétique est une des principales solutions pour pallier ce risque majeur, et constitue une priorité pour la profession (de l'ordre de 10000 emplois directs, et autant d'emplois induits, à plein temps). Ce progrès génétique ne pourra se traduire au niveau industriel que par un renoncement à la technique traditionnelle du captage d'huîtres sauvages au profit d'un approvisionnement à partir des écloseries-nurseries. Aux États-Unis (côte ouest), $80 \%$ de la production passe déjà par cette voie. En France, la progression est régulière, mais ne concerne que $10 \%$ de la production pour I'instant. Le recours aux produits d'écloserie tendra à se généraliser dès que les premiers produits de la sélection génétique seront sur le marché. La sélection des huîtres plates résistantes à Bonamia sont prévues pour une échéance proche, et les travaux sont d'ores et déjà engagés pour la sélection d'une souche de $C$. gigas à l'immunité renforcée.

Un recours plus systématique aux écloseries est donc souhaitable à terme. Il sera d'autant plus facile à obtenir de la profession que les techniques seront maîtrisées et les coûts abordables. C'est pourquoi les recherches portent sur l'amélioration des techniques d'écloserie, et notamment l'alimentation larvaire à base de microalgues.

\section{Prégrossissement intensif de coquillages}

Certaines espèces de microalgues comme la diatomée Skeletonema costatum sont utilisées pour le prégrossissement intensif en nurserie de coquillages d'intérêt commercial (huîtres creuses, plates et palourdes). Elles sont cependant inféodées à la présence d'eaux salées souterraines utilisées comme milieu de culture (voir «Maîtrise de la production photoautotrophe » supra).

Ainsi après une mise au point de quelques années, cette technique permettant de faire croitre de mars à novembre de jeunes bivalves de 4 à $10 \mathrm{~mm}$ a été transférée aux conchyliculteurs de la façade atlantique (Vendée, Charente Maritime). À ce jour, 20 entreprises artisanales I'utilisent et produisent quelques 150 millions de naissains de bivalves par an, soit un chiffre d'affaires de l'ordre de $9 \mathrm{MF}$.

\section{Télécaptage de l'huître creuse}

Les microalgues, et en particulier S. costatum, peuvent également être utilisées de manière différée pour le télécaptage de jeunes huîtres issues d'écloserie. Cette technique consiste à transporter des larves compétentes pour la métamorphose et à les immerger dans un bassin contenant des supports (capteurs) afin d'effectuer sur place la fixation qui permettra un élevage ultérieur. Dans ce cas, le phytoplancton (diatomées, flagellés) peut être concentré par centrifugation, puis conservé au froid modéré $\left(5^{\circ} \mathrm{C}\right)$ avec des conservateurs, ou congelé à $-20^{\circ} \mathrm{C}$, ou mieux à $-80^{\circ} \mathrm{C}$. Cette nourriture est ensuite diluée à la concentration voulue dans les bassins de télécaptage et permet d'assurer la fixation des jeunes huîtres dans de bonnes conditions. Ce marché peut représenter de 5 à $10 \%$ des besoins en naissain de l'ostréiculture nationale.

\section{Affinage de l'huître creuse}

Le phytoplancton est utilisé également comme algue fourrage pour assurer l'affinage contrôlé d'huîtres creuses destinées à la commercialisation. Des techniques intensives basées sur la production de grands volumes extérieurs $\left(100 \mathrm{~m}^{3}\right)$ de la diatomée Skeletonema costatum sur eau salée souterraine permettent, en 30 jours avec des températures situées entre 8 et $12^{\circ} \mathrm{C}$, de multiplier par 2 le poids sec et par 3 la quantité de glycogène contenue dans la chair de l'huître. Récemment des techniques semi-intensives basées sur l'amendement d'eau de mer et la production de microalgues fourrage, permettent d'envisager à court terme un affinage des huîtres creuses dans la plupart des zones 
des marais maritimes. Ces nouveaux procédés concourent à faire évoluer les pratiques traditionnelles (secteur de Marennes - Oléron) vers une meilleure maîtrise de la qualité du produit fini, par un meilleur contrôle des conditions d'affinage.

Lors de l'affinage, les microalgues transforment également la qualité des huîtres creuses sur le plan sensoriel. Des études récentes de I'IFREMER et de I'ENITIAA de Nantes ont montré qu'avec certaines espèces de microalgues, le goût et l'arôme du produit étaient modifiés. Des techniques instrumentales ( "headspace ", "sniffing ") et sensorielles (panel de testeurs) se recoupent pour mettre en évidence chez I'huître affinée un marquage gustatif et aromatique d'origine phytoplanctonique. Ces travaux peuvent déboucher sur la mise en place de procédés permettant la labellisation des produits, et donc un gain en valeur ajoutée pour quelques espèces de coquillage destinées à la commercialisation.

\section{La couleur des huîtres}

Le verdissement de l'huître, qui consiste dans l'acquisition en phase finale d'engraissement d'une couleur bleu vert au niveau des branchies et des palpes labiaux des mollusques bivalves, valorise suffisamment le produit pour représenter un enjeu économique important. Effectuée traditionnellement en claire, cet affinage peut également être assuré par mise au contact direct des huîtres avec l'agent colorant responsable, produit en conditions contrôlées. Il s'agit d'un pigment hydrosoluble, excrété par la diatomée Haslea ostrearia Simonsen, dont la culture a été mise au point par I'université de Nantes (ISOMer). La société SOPROMA de Bouin (Vendée) propose le service consistant dans le verdissement accéléré de I'huître (marché de l'ordre de $40 \mathrm{MF}$ pour $4 \mathrm{~F} / \mathrm{kg}$ d'huître). Pour cela, la microalgue est cultivée séparément en conditions contrôlées, et les cultures servent à ensemencer des claires de verdissement. Toutefois, il est proposé un autre procédé consistant en la séparation du pigment par centrifugation ou filtration tangentielle. L'huître est ensuite immergée pendant 12 heures dans une eau enrichie en ce pigment concentré. Les techniques de culture $d^{\prime} H$. ostrearia et de récolte du pigment sous diverses formes font l'objet d'une recherche dont dépend la rentabilité finale de I'activité. L'évaluation de l'aptitude d' $H$. ostrearia à la production en photobioréacteur a été retenue au titre de l'appel à propositions «Biotechnologies " du secrétariat d'État à la Recherche et de I'ANVAR (octobre 1996).

\section{Environnement}

\section{Utilisations potentielles des microalgues toxiques}

Diverses microalgues du phytoplancton marin, appartenant pour la plupart à la classe des dinoflagellés, produisent des toxines pouvant entraîner des mortalités de poissons et/ou une contamination des coquillages avec des conséquences néfastes variables pour l'homme, selon le type et la quantité de toxines accumulées. Les événements toxiques sur les côtes françaises métropolitaines, dont I'IFREMER assure la surveillance dans le cadre du réseau phytoplancton (RÉPHY), sont dus à la présence de trois grands types de toxines : paralysantes, diarrhéiques et néfastes pour la faune et la flore. Leur étude présente un intérêt potentiel dans les applications pharmacologiques et en cytologie, car certaines agissent en inhibition ou activation du métabolisme cellulaire. L'obligation de surveillance implique de détecter soit les toxines soit les espèces qui les produisent : il est envisageable de tirer parti de leurs spécificités pour des applications à cette surveillance.

\section{Les toxines et les espèces}

L'acide okadaïque et certains de ses dérivés responsables des intoxications diarrhéiques possèdent des propriétés physiologiques très intéressantes : ce sont des inhibiteurs spécifiques et puissants des protéines phosphatases 1 et $2 \mathrm{~A}$. Ce mécanisme d'action entraîne d'autres propriétés, plus particulièrement un effet promoteur de tumeurs et une action positive sur la contraction des muscles lisses. D'autres activités sont également citées dans 
la littérature : actions antibactériennes et antifongiques, effets cytotoxiques, etc.

La saxitoxine impliquée dans les événements à Alexandrium minutum a certaines propriétés spécifiques. C'est un agent bloquant sélectif des canaux sodium. De ce fait, elle a une action sur la plaque neuromusculaire, sur la contractibilité du diaphragme et sur le potentiel d'action du nerf phrénique. Les toxines ichthyotoxiques dérivées de l'acide gras all-cis octadécapentaénö̈que sont des inhibiteurs non spécifiques d'ATPases de surface $\left(\mathrm{H}^{+}, \mathrm{Na}^{+}, \mathrm{K}^{+}, \mathrm{Cl}^{-}\right)$. L'utilisation de ces toxines à faible dose pourrait éventuellement mettre en évidence des spécificités intéressantes, aujourd'hui à l'étude. Gymnodinium mikimotoi produit de plus des sesquiterpènes (épicubénol, alpha-cadinol et cubénol) cytotoxiques dont l'action n'a pas été étudiée en détail.

\section{Mise en culture et production de toxines}

\section{Acide okadaïque (AO)}

Aucune espèce de Dinophysis spp. n'est cultivable en l'état actuel des connaissances. À défaut, plusieurs souches de Prorocentrum lima, espèce présente dans le microphytobenthos des zones ciguatériques, sont cultivées dans différents laboratoires. Six souches sont entretenues en «batch » à I'IFREMER. Les trois souches provenant d'Espagne produisent de l'acide okadaïque et différents dérivés acyl et diol-esters. Les toxines produites par les trois autres souches (Floride, Nouvelle-Calédonie et Saint-Barthélemy) font l'objet $d^{\prime} u n e$ étude en cours. Le passage à des productions importantes ne serait pas immédiat du fait des conditions particulières de croissance de ce dinoflagellé benthique (nécessité $d$ 'un substrat). Par ailleurs, cette espèce présente de faibles taux de croissance $(0,1-0,15 \mathrm{div} / \mathrm{jour})$. Les techniques d'extraction et de purification à $95 \%+$ de l'acide okadaïque sont maîtrisées.

Pour produire $1 \mathrm{mg}$ d'acide okadaïque purifié, il faut disposer $\mathrm{d}^{\prime} \mathrm{un}$ minimum de $10 \mathrm{~g}$ de matière algale sèche soit environ $1,5.10^{9}$ cellules de la souche PL2V. Les prix de vente pratiqués en 1996 varient de 2000 à $4000 \mathrm{~F}$ les $100 \mu \mathrm{g}$ pour l'acide okadaïque issu de microalgues. Les activités pharmacologiques largement décrites dans la littérature sont assez diverses pour justifier un marché rentable. Cinq firmes françaises commercialisent déjà l'AO produit à l'étranger. En revanche, le facteur clé en terme de production de toxine reste le taux de croissance très faible des souches cultivées, qui nécessite des études supplémentaires sur les techniques de culture. Des essais de microencapsulage ou de cellules immobilisées dans des mousses pourraient être réalisés selon les protocoles mis au point par divers laboratoires.

\section{Saxitoxine et dérivés}

Plusieurs espèces et souches $d^{\prime}$ Alexandrium sont disponibles dans différentes collections. L'IFREMER entretient trois souches: $A$. tamarense MOG 835 (Japon) 8 gonyautoxines - $A$. fundyense Cana$\mathrm{da}, 7$ gonyautoxines - $A$. minutum France, baie de Morlaix, 3 gonyautoxines. Le taux maximum de division est plus fort que celui de $P$. lima, mais ces espèces sont très sensibles à l'agitation nécessaire si l'on envisage une production importante en continu d'algues présentant un profil toxinique constant. De ce fait, les conditions optimales de production en grandes quantités devraient faire l'objet d'une étude. Les procédures d'extraction et de purification sont maîtrisées.

Pour produire $1 \mathrm{mg}$ de GTX2/GTX3 purifiées, il faut disposer d'un minimum de $5 \mathrm{~g}$ de matière algale sèche soit environ $10^{9}$ cellules. Les prix de vente 1996 vont de 300 à $1500 \mathrm{FF}$ les $100 \mu \mathrm{g}$ pour la saxitoxine et atteignent le double pour les gonyautoxines.

\section{Ichthyotoxines}

Quatre souches ichthyotoxiques originales sont maintenues et étudiées à l'IFREMER. Il s'agit de : Gymnodinium mikimotoi Tinduff 87 - G. mikimotoi Tinduff 95, Gymnodinium sp. Bou Grara, Tunisie, 1993 - Heterosigma akashiwo Camaret 94. Les toxines $\mathrm{d}^{\prime} \mathrm{H}$. akashiwo ne sont pas encore connues. Les trois autres souches produisent un acide gras inhabituel : I'acide octadécapentanoïque qui est libre ou sous forme diacyl-glycoglycérol. La fonction sucre est composée majoritairement de digalactosyl. Un dispositif expérimental de production en continu de Gymnodinium est en fonction à l'IFREMER. Cependant, du fait de la sensibilité excessive à l'agitation de ces espèces, il n'est pas possible d'envisager des productions importantes de cette algue. De ce fait, la synthèse de l'acide gras libre a été réalisée, et il est possible de synthétiser des quantités de l'ordre de $100 \mathrm{mg}$ à partir d'huile de foie de morue avec 
un matériel de laboratoire standard. La production des composés acylés serait plus délicate du fait de la grande labilité de l'acide gras. Ces composés ne sont pas sur le marché, lequel n'a pas encore été prospecté.

D'une façon générale, les coûts de production des microalgues toxiques ne sont pas encore connus, et des essais seraient à faire pour déterminer la rentabilité d'une éventuelle initiative commerciale.

\section{Applications à la surveillance de I'environnement}

Les différentes espèces nuisibles sur les côtes françaises sont observées dans le cadre du RÉPHY. La détermination de certaines d'entre elles requiert des compétences difficiles à acquérir. Des identifications erronées peuvent se produire. Par ailleurs, la limite d'alerte pour Dinophysis est de 200 cellules/l : ceci correspond à 2 cellules observées au microscope. Étant donné la surdispersion des populations naturelles, la définition d'une telle limite est entachée d'erreur. Le comptage sur des volumes plus importants est le plus souvent difficile, sinon impossible du fait de la présence d'autres algues, de floculats organiques et de matériel particulaire.

Une approche moléculaire permettrait de pallier partiellement ces inconvénients. En effet, le diagnostic fiable de présence d'ADN de microorganismes recherchés dans des échantillons est désormais théoriquement possible grâce aux outils de la biologie moléculaire. La réalisation pratique de tels travaux suppose de disposer préalablement de connaissances scientifiques de base.

Une sonde nucléique a pour objet de mettre en évidence une séquence d'ADN préalablement connue : ADN codant pour la synthèse d'une séquence constituant un marqueur taxonomique spécifique (ARN ribosomal, protéine), ADN codant pour une protéine antigénique, $A D N$ codant pour une enzyme caractéristique de la synthèse d'une molécule à effet toxique. L'interrogation d'une base de séquences (SRS/Genbank) nous a permis de constater que des séquences d'ARN ribosomal étaient disponibles pour 34 microalgues pertinentes. Parmi ces séquences, celles de l'ADN codant pour l'ARNr 24S (ADN $24 S$ ) sont les plus nombreuses. C'est donc par l'emploi de séquences d'intérêt taxonomique (et non de celles associées à la production de toxines) que la mise en œuvre de sondes nucléiques serait a priori la plus aisée.

Le développement de sondes nucléiques comme outil de diagnostic supposerait préalablement :

- L'analyse des séquences disponibles, ce qui pourrait déboucher sur des travaux de séquençage complémentaires sur les organismes de référence de façon à disposer d'un cadre taxonomique et phylogénique convenable ;

- Le séquençage de l'ADN 24S (par exemple) d'organismes trouvés sur les côtes françaises de façon à valider leur positionnement taxonomique, examiner leur diversité et à les situer par rapport aux références disponibles. Ces travaux seraient idéalement effectués sur de l'ADN de cultures pures ou de cellules isolées. Cependant, un ADN extrait d'un mélange d'espèces pourrait probablement aussi être étudié grâce à une technique appelée DGGE (Denaturing Gradient Gel Electrophoresis) récemment appliquée à la caractérisation des communautés naturelles de microorganismes ;

- La confrontation de l'ensemble de ces résultats devrait permettre la mise en évidence de séquences cibles utilisables pour l'identification d'espèces ;

- De telles séquences cibles devraient permettre ensuite de révéler, en étudiant l'ADN de filtrats par $\mathrm{PCR}^{15}$ quantitative, par exemple, la présence ou l'absence de séquences d'ADN d'espèces recherchées.

- Des analyses de corrélation seraient ensuite nécessaires afin d'étudier la correspondance entre I'obtention de réponses positives en PCR et la présence au microscope de cellules de l'espèce recherchée, puis la correspondance entre l'obtention de réponses positives en PCR et la présence de toxines.

Ce n'est qu'à l'issue de ces différentes étapes que la mise au point d'un outil moléculaire de routine pour l'identification de microalgues toxiques pourrait être envisagée.

Le développement de sondes nucléiques pour l'identification de microalgues toxiques repose donc sur celui d'un nouveau programme de 
recherche spécifique (il ne s'agit pas simplement de l'application d'une méthode disponible) qu'il conviendrait raisonnablement de focaliser, en un premier temps, sur le genre pour lequel les informations génétiques disponibles sont les plus nombreuses : Alexandrium.

En conclusion, la production des toxines paralysantes très substituées (toxines $\mathrm{C}$ ) pourrait secondairement présenter un intérêt économique. Dans le cadre de la mission d'observation des efflorescences toxiques de I'IFREMER, la mise au point de techniques de détection d'espèces suspectes présente un intérêt prioritaire en permettant d'éviter les erreurs d'identification, d'améliorer la précision du dénombrement et, éventuellement, de détecter des introductions accidentelles de génotypes non indigènes. La détection des toxines elles-mêmes par immunofluorescence est plus difficile à mettre en œuvre du fait de la grande variété de composés de substitution dans une même espèce. De telles techniques, qui restent à développer, seraient applicables au niveau national dans un premier temps, avant de l'être éventuellement dans le cadre des réseaux de surveillance européens.

\section{Épuration des effluents de l'aquaculture intensive}

L'utilisation des microalgues marines pour traiter I'azote (NH4 et N03) et le phosphore dissous des effluents d'aquaculture est une adaptation nou- velle de techniques classiques de traitement de l'eau douce par lagunage.

L'IFREMER a développé depuis deux à trois ans deux actions de recherche complémentaires dans ce domaine :

- La station de Palavas, en collaboration avec I'université de Montpellier (thèse de docteur d'université), étudie le lagunage à haut rendement comme système d'épuration dans une boucle secondaire de traitement des rejets, issus d'une boucle primaire de recyclage des eaux d'élevage, afin de pouvoir les réutiliser pour atteindre un recyclage complet ;

- Le CREMA-L'Houmeau, avec le soutien du département de la Charente-Maritime, d'un aquaculteur privé et du CNRS, étudie la production de masse de diatomées marines en réacteurs naturels afin d'améliorer les systèmes existants de lagunage simple avant rejet en zone conchylicole.

Cette problématique a un potentiel de développement important avec la montée du concept d'aquaculture "durable ", qui va devenir un objectif essentiel pour le troisième millénaire dans le monde entier. Les enjeux sont économiques, avec la diminution des besoins en eau des fermes marines et l'amélioration de la qualité des eaux d'élevage, et sociaux, avec l'amélioration de l'intégration de I'aquaculture de poissons marins et de crevettes dans l'environnement, et la diminution des contraintes pour le choix des sites d'implantation. 


\section{Chapitre II}

\section{Autres thèmes}




\section{Alimentation}

\section{Homme}

La première installation industrielle d'une capacité supérieure à $1 \mathrm{t} /$ mois a été mise en service au Japon dans les années soixante. Il s'agissait de la chlorophycée Chlorella, microalgue dominante vendue comme supplément alimentaire (diététique) sous forme de pilule. La production industrielle de la cyanobactérie Spirulina, de consommation traditionnelle dans certains pays, a démarré en 1974 au Mexique. Cette algue est plus facile à produire que la chlorelle en raison de sa résistance aux forts $\mathrm{pH}$, et donc aux contaminations. Ses qualités nutritionnelles certaines $(60 \%$ de protéines, $7 \%$ de lipides, GLA, vitamines), voire thérapeutiques (cicatrisant, coupe-faim, etc.) en font un nutraceutique recherché en même temps qu'un aliment de subsistance pour les populations des régions chaudes. La production s'est étendue aux régions d'Asie du Sud-Est et du Pacifique. Elle est le fait d'installations de toutes tailles, depuis les bassins familiaux de quelques mètres carrés jusqu'aux installations industrielles de plusieurs hectares. Outre l'évaporateur mexicain de Sosa Texcoco (12 ha, $500 \mathrm{t} / \mathrm{an})$, plusieurs fermes de plus de 200 t/an sont en exploitation, notamment en Californie (Earthrise), à Hawaii (Cyanotech) et à Taïwan. Aujourd'hui, la production annuelle mondiale de spiruline dépasse le millier de tonnes par an, avec un prix de gros moyen en France ${ }^{16}$ de $175 \mathrm{~F} / \mathrm{kg}$. L'habilitation des microalgues pour l'alimentation humaine ne porte en Europe que sur la chlorelle et la spiruline. D'autres candidats sont en lice, notamment $P$. cruentum.

\section{De nouvelles sources d'AGPI à trouver}

L'élevage intensif des poissons est fondé sur l'utilisation d'aliments secs composés d'environ 30 à $60 \%$ de farines et 10 à $20 \%$ d'huiles de poissons marins (clupéidés). Pour des raisons d'essentialité en acides gras polyinsaturés à longue chaîne, la pisciculture est dépendante des lipides d'origine marine. Dans une perspective de croissance de I'aquaculture et de stagnation de la pêche, les farines et les huiles de poisson issues de cette dernière seront insuffisantes au début du siècle, ne pouvant couvrir tous les besoins en aliments composés de l'aquaculture intensive. Si les besoins en carbohydrates et protéines semblent pouvoir être couverts par les matières premières d'origine terrestre, quelles seront les nouvelles sources d'acide gras essentiels, notamment ceux des séries C20 et C22 pour les besoins de l'aquaculture, des animaux terrestres et de l'homme?

Ce déficit va probablement nécessiter un changement radical dans les comportements, avec l'apparition de nouvelles sources. Bien qu'aujourd'hui exclue compte tenu des coûts de production, l'utilisation du phytoplancton marin comme source industrielle d'AGPI reste une solution potentielle à examiner pour le futur. Elle pourrait même couvrir une part des besoins en protéines, car celles-ci sont présentes en teneurs élevées dans cette biomasse.

\section{Poissons}

L'utilisation des microalgues en aquaculture de poissons est actuellement importante dans deux segments de l'écloserie (cultures et enrichissement de rotifères, milieu d'élevage larvaire) et de I'agro-alimentaire spécifique (aliments de proies et de larves). Elle pourrait aussi le devenir en agroalimentaire de grossissement (aliments artificiels).

\section{Culture et enrichissement de rotifères}

L'utilisation de proies vivantes, notamment du rotifère $B$. plicatilis, est actuellement un impératif de succès en écloserie de poissons marins à larves petites. La culture de ces proies avec des aliments artificiels à base de levures est possible, mais beaucoup moins performante qu'avec du phytoplancton. L'intérêt des microalgues se situe à 3 niveaux :

- restauration rapide des populations de rotifères à exploiter après des catastrophes ( 7 à 13 jours contre 20 à 35 jours avec des levures) ;

- meilleure qualité nutritionnelle des proies ;

- moindre contamination bactérienne (notamment en vibrions).

\section{Milieu d'élevage larvaire de poissons}

Chez de nombreuses espèces de poissons d'eau douce et d'eau de mer, l'introduction de phytoplancton dans les bassins d'élevage larvaire 
conduit à des résultats de survie, croissance, et indice de transformation alimentaire bien meilleurs que lorsque l'élevage est réalisé en eau claire. Chez la daurade, cette condition est même un impératif de production économique.

Les raisons du rôle positif des microalgues dans les bassins d'élevage larvaire ne sont pas encore entièrement comprises, car les cultures phytoplanctoniques sont des milieux complexes de matières en suspension (vivantes ou mortes) et solubles, organiques ou non. L'amélioration de la qualité de l'eau par oxygénation, stabilisation du $\mathrm{pH}$, etc. est une certitude, mais n'explique pas tout. Le rôle nutritionnel direct ou indirect (via les rotifères) est également certain.

Si la fonction énergétique ne peut être retenue du fait de la faiblesse des doses distribuées, les fonctions vitaminiques, inductrices de processus comportementaux (prise initiale de nourriture) ou physiologiques (lipoprotéinogénèse intestinale), l'excrétion de substances solubles directement assimilables par les larves (glucose) sont confirmées. $\mathrm{D}^{\prime}$ autres fonctions positives comme la régulation de populations bactériennes, I'effet probiotique, l'immunostimulation non spécifique par augmentation des protections membranaires (sécrétions muqueuses stimulées par la néoglycogénèse), le début de stimulation antigénique par glucanes de parois, etc. sont toutes constatées mais pas encore suffisamment étudiées pour être comprises (donc suffisamment analysées pour être utilisées sous d'autres formulations que le produit brut).

Les qualités non conventionnelles (i.e. non encore comprises) des microalgues les font parfois utiliser empiriquement sous diverses formes dans des compositions alimentaires pour l'écloserie ou l'aquariologie. Souvent assumé par des spirulines aujourd'hui, ce marché pourrait être diversifié par des microalgues marines plus performantes dans l'avenir.

\section{Le marché des microalgues pour la larviculture des poissons}

L'offre d'un produit consistant dans des cellules vivantes concentrées, de la pâte congelée ou lyophilisée, etc. à prix compétitif conduirait certainement à un changement radical des techniques de production de proies (donc de larves) en écloserie. En effet, la culture des algues en écloserie introduit des charges importantes en main d'œuvre et amortissement d'installation, que les producteurs souhaitent minimiser. Ils devraient être preneurs de pâte de microalgue s'ils sont convaincus de son efficacité, ce que laissent espérer les résultats de recherche et leur validation (programme MANTA ${ }^{17}$ ), et s'ils y trouvent un avantage financier, ce qui nécessite des prix de mise en marché plus bas que les coûts de production interne.

Comme le fait apparaître notre analyse (voir "Coût de revient des microalgues produites en phototrophie ", supra), le coût de revient de la biomasse produite dans les installations d'aquaculture est très sensiblement plus élevé que celui des photobioréacteurs à couche mince. Or ce constat est loin d'être admis puisque le premier est réputé de l'ordre de 1000 et $1400 \mathrm{FF} / \mathrm{kg}^{18}$, poids sec. Celui des installations spécialisées de grande taille étant d'environ $1500 \mathrm{FF} / \mathrm{kg}^{19}$, poids sec, on comprend mieux l'absence de demande, d'autant qu'à ce prix s'ajoutent ceux du transport, du stockage et de la distribution.

La mise en œuvre des techniques récentes de production et de préservation pourrait donc créer une situation favorable à l'émergence de nouveaux produits. C'est ainsi qu'au Japon, des microalgues du genre Chlorella enrichies en vitamine B12 sont déjà commercialisées sous forme de pâte congelée pour les cultures de rotifères. Sur la base des productions aquacoles actuelles en Europe, la production d'algues pour les écloseries est estimée à 3-4 tonnes/an, soit un chiffre d'affaires compris entre 4 et 5 MFF. À ce marché devrait s'ajouter celui de l'aquariophilie, difficile à évaluer.

\section{Les développements en cours}

Un fort potentiel de recherche international est mobilisé sur la nutrition des larves de poisson, ciblé principalement sur les acides gras et les aliments inertes, où les algues interviennent face à d'autres produits substitutifs. 


\section{Chimie fine}

\section{Antioxydants}

L'oxygène moléculaire est indispensable à de nombreux êtres vivants. Son assimilation in vivo engendre la formation de dérivés toxiques (formes actives de l'oxygène et radicaux libres) éliminés par la cellule par différents mécanismes de défense. Les microalgues produisent aussi par photosynthèse de l'oxygène moléculaire et possèdent donc des systèmes antioxydatifs particulièrement développés. Par antioxydant, on considère toute substance, présente à faible concentration comparée à celle des "substrats oxydables", capable de réduire significativement ce ou ces substrats ${ }^{20}$. Chez les microalgues on trouve des composés de nature biochimique variée capables, seuls ou en association, de métaboliser efficacement les espèces réactives de l'oxygène. C'est ainsi le rôle joué par : les caroténoïdes, notamment le $\beta$-carotène vis à vis de l'oxygène singulet ${ }^{1} \mathrm{O}_{2}$, les enzymes de la famille des superoxyde dismutases (SOD), les tocophérols (Vit E) et l'ascorbate (Vit C) vis à vis de I'anion superoxyde $\mathrm{O}_{2}^{-}$, les enzymes de type catalase, glutathion peroxydase vis à vis du peroxyde d'hydrogène $\mathrm{H}_{2} \mathrm{O}_{2}$. D'autres composés tels la taurine et d'autres aminoacides soufrés, le glutathion, l'acide urique pourraient aussi exercer une activité antioxydante.

L'intérêt pour ces substances antioxydantes est vif depuis une quinzaine d'années du fait de la mise en évidence du rôle des formes réactives de l'oxygène et des radicaux libres oxygénés dans diverses pathologies chroniques (athérosclérose, arthrose, cataracte, cancer, Parkinson...) ou aiguës (inflammation, choc septique, lésions de reperfusion... $)^{21}$. La question des thérapies antioxydantes est largement ouverte ${ }^{22}$ et semble constituer une voie de recherche \& développement prometteuse. Les microalgues pourraient y trouver des créneaux de valorisation spécifiques. La SOD de la microalgues rouge $P$. Cruentum est ainsi envisagée en thérapie adjuvante du SIDA pour réduire les effets du virus chez les séropositifs : I'infection augmente la production de radicaux libres qui activent la réplication virale.
D'autres formes d'utilisation de cette enzyme sont aussi proposées, comme le traitement des fibroses de la peau induites lors des radiothérapies. En terme de développement, ces utilisations visent le moyen terme (3-6 ans), et d'autres créneaux à plus court terme devraient voir le jour. L'utilisation $d^{\prime}$ extraits de microalgues à forte teneur en antioxydants doit notamment se positionner dans le marché des nutraceutiques et aliments santé, marché en forte croissance au Japon et aux États-Unis.

\section{Pigments}

\section{Phycobiliprotéines}

Les propriétés colorantes et fluorescentes de la phycoérythrine (rouge) et de la phycocyanine (bleue) sont exploitées pour le diagnostic en recherche et médecine (30 000 à $70000 \$$ US $/ \mathrm{kg}$ d'extrait purifié) et en industrie alimentaire (200 à $5000 \$$ US $/ \mathrm{kg}$ de produit à $20 \%$ ). Ces phycobiliprotéines sont synthétisées par les cyanobactéries (spiruline) et certaines microalgues rouges (P. cruentum) dont la production commerciale est assurée en conditions très contrôlées dans des photobioréacteurs. Le marché potentiel annuel est supérieur ${ }^{23}$ à 50 millions de $\$$ US, avec une croissance de $10 \%$ par an.

\section{Caroténoïdes}

Le $\beta$-carotène est un pigment orange très utilisé comme additif et agent colorant en industrie de l'alimentation et comme composant en industrie pharmaceutique, cosmétologique et diététique. Le marché mondial (ibid.) est estimé à 150 à 250 millions de $\$$ US, ce qui représente 300 à 400 tonnes (500 \$ US/kg), en augmentation de $20 \%$ par an (1992).

La chimie de synthèse à partir de la $\beta$-ionone est la source principale, avec F. Hoffmann-La Roche pour les produits huileux ( $80 \pm 5 \%$ du marché) et BASF pour les produits en poudre. Dans ce contexte, les produits d'origine naturelle représentent $10 \pm 2 \%$, pour une valeur de l'ordre de 20 à 30 millions de \$ US. La production de $\beta$-carotène à partir de 
la chlorophycée halophile Dunaliella salina est assurée principalement par deux grandes compagnies australiennes (Betatene et Western Biotechnology) - qui détiennent environ $60 \%$ du marché, deux compagnies des États-Unis (Nutralite et Cyanotech), et une compagnie israélienne (Nature Beta Technologies). Résistant bien aux fortes salinités où elle ne craint aucune compétition, cette microalgue est produite dans des étendues lagunaires à ciel ouvert. Elle est vendue comme nutraceutique à un prix compris entre 800 à $1800 \$$ US/kg, selon la formulation, soit environ le double de celui des produits de synthèse.

Un autre caroténoïde important produit par les microalgues est I'astaxanthine. Avec la canthaxanthine, ce pigment rose est le seul qui soit fixé par le muscle des salmonidés d'élevage, dont la coloration représente un marché de 100 millions de \$ US par an (1994), en rapide expansion. Il est détenu majoritairement par le suisse F. Hoffmann-La Roche, qui produit cet additif de I'alimentation animale par synthèse, et le propose au prix de $3000 \$ \cup S / k g$. Les produits naturels font l'objet d'une demande croissante, avec une augmentation de $20 \%$ par an. Actuellement, la seule fourniture est assurée par le Hollandais Gist Brocades avec sa levure Phaffia rhodozyma, malgré des teneurs faibles $(0,4 \%)$. La chlorophycée d'eau douce Haematococcus pluvialis produit de I'astaxanthine à des teneurs pouvant atteindre

\section{Environnement}

\section{Épuration du $\mathrm{CO}_{2}$}

La pollution atmosphérique a pris un caractère planétaire avec, en particulier, l'augmentation des rejets de gaz carbonique faisant suite à l'utilisation intensive de combustibles fossiles. Le cycle du carbone comprend une partie océanique encore mal connue dans laquelle l'activité biologique de surface joue un rôle important.

Des programmes internationaux ont été mis en place pour étudier, au niveau de l'océan planétaire, les phénomènes de mobilisation de $\mathrm{CO}_{2}$ sous forme de calcaire par les organismes marins phytoplanctoniques dont la contribution apparaît essentielle. Dans ces travaux, les microalgues
$5 \%$ du poids sec, mais les coûts de production sont encore trop élevés. En réduisant sensiblement ces coûts, notamment par les progrès de la technologie des photobioréacteurs, certaines compagnies (Algatec-Suède, Norbio-Norvège, Biotechna-GB, Thallia Pharmaceuticals-France, Aquasearch, Maricultura, Danisco Biotechnology, Oceancolor - États-Unis...) espèrent entrer dans la compétition.

\section{Marquage moléculaire aux isotopes stables}

Des composés biochimiques marqués à l'aide $d^{\prime}$ isotopes stables (BIS) peuvent être obtenus par métabolisation de ces isotopes $\left(\mathrm{D},{ }^{13} \mathrm{C},{ }^{15} \mathrm{~N}\right)$ lors de la réaction de photosynthèse dans des réacteurs parfaitement contrôlés à l'égard des fluides entrant et sortant. Ces BIS sont utilisés dans la recherche sur la structure moléculaire et dans l'ingénierie des médicaments rationnels, c'est à dire exploitant la connaissance des relations structure-fonction. Les BIS aident les chercheurs à développer plus efficacement de nouvelles molécules en leur permettant de déterminer la structure tridimensionnelle de certaines protéines en solution et d'étudier les caractéristiques de ces structures, comme ce fut le cas pour la gonadotropine chorionique humaine (Gch), par exemple. La société Martek (États-Unis) a réalisé un chiffre d'affaire supérieur à 1 million de \$ US (1993) grâce à la vente de ses BIS.

sont étudiées pour permettre de caler des modèles destinés à prévoir les tendances à long terme. L'emploi des microalgues est également envisagé comme agent d'épuration pour réduire les rejets de $\mathrm{CO}_{2}$ dans l'atmosphère et produire des substances chimiques à haute valeur ajoutée, essentiellement au Japon.

L'organisme de référence est le coccolithophoride Emiliania huxleyi, pour sa production de fines particules de calcite (coccolithes) dont I'utilisation peut être envisagée dans de nombreuses applications industrielles (électronique) et dans le domaine de la médecine (Ca et ostéoporose). 
Récemment cependant, des isolements systématiques de souches algales issues de divers milieux côtiers ou extrêmes, et ce effectué sous des conditions stressantes, ont permis l'obtention de nouvelles souches.

Ainsi, la chlorophycée Chlorococcum littorale s'est révélée résistante à des concentrations élevées de $\mathrm{CO}_{2}$ (jusqu'à $20 \%$ ), ce qui a engendré tout un nouveau champ de recherches : I fixation du $\mathrm{CO}_{2}$ des rejets de l'industrie lourde. Ceci implique à la fois des études de technologie (mise au point de photobioréacteurs, de collecteurs d'énergie solaire), de physiologie, d'optimisation de la croissance et de recherche d'applications potentielles pour la biomasse ainsi produite.

\section{Énergie}

\section{Hydrocarbures}

Certaines espèces de microalgues, en particulier la chlorophycée Botryoccocus braunii, produisent des composés lipidiques à longue chaîne présentant une grande diversité de structure chimique. Cette faculté d'accumulation d'hydrocarbures a été étudiée de façon approfondie, notamment suite aux chocs pétroliers successifs des anınées soixante-dix. En dépit de résultats intéressants, et compte tenu des coûts élevés de production des microalgues, qui sont aujourd'hui supérieurs au moins d'un facteur 10 à ceux des hydrocarbures fossiles, il est peu probable qu'elles constituent une solution énergétique alternative à court terme.

\section{Production d'hydrogène}

L'intérêt pour l'hydrogène biologique est réapparu au début des années quatre-vingt-dix lorsqu'il est devenu évident que la pollution atmosphérique par combustion des carburants fossiles était non seulement dangereuse pour la santé mais pourrait, de surcroît, être une cause des changements climatiques planétaires. Par son caractère renouvelable et non polluant, I'hydrogène biologique est l'un des meilleurs candidats pour succéder aux hydrocarbures, et les enjeux attachés à cette forme d'énergie sont donc considérables.

\section{Support de la vie dans l'espace}

En vue de préparer des vols spatiaux de longue durée, les agences spatiales américaine, russe et, plus récemment, européenne travaillent à la définition des systèmes de support de la vie. Par delà le vol Terre-Lune, en effet, I'autonomie devient nécessaire à l'égard de l'oxygène, de l'eau et de la nourriture de base. Des expériences de longues durée ont montré que les microalgues (Chlorella, Spirulina) sont aptes à la fourniture d'oxygène et d'eau à l'homme, mais également à l'utilisation de ses déchets liquides et gazeux. Outre la recherche $d^{\prime}$ une adéquation entre respiration humaine et assimilation par l'algue, les développements portent sur des réacteurs à couche mince fonctionnant en microgravité.

$C^{\prime}$ est ainsi que les moteurs cryogéniques et la pile à combustible font I'objet de R\&D intensifs pour la propulsion des fusées et des automobiles, respectivement.

Certains microorganismes phototrophes peuvent produire de l'hydrogène, évitant le recours aux énergies à haut niveau du vapo-cracking et de l'électrolyse, qui font aujourd'hui appel à des ressources non renouvelables. Pour cela, deux voies sont explorées par différents laboratoires dans le monde, dont notamment en Europe ceux de P.M. Vignais (CEA, Grenoble), et de D.O. Hall (King's College, Londres), respectivement :

- Les bactéries phototrophes : elles sont capables de produire I'hydrogène moléculaire lors de la réduction directe des protons de l'eau par la nitrogénase dans une réaction ATP dépendante. Les conditions de croissance consistent dans I'anaérobiose, une forte intensité lumineuse, une métabolisation effective du substrat et des apports limités d'azote. Des cultures de la bactérie pourpre non sulfureuse Rhodobacter capsulatus ont ainsi produit de I'hydrogène et du $\mathrm{CO}_{2}$ à partir de lactate et de succinate à un rendement de $72 \%$ du maximum théorique, soit de l'ordre de $130 \mathrm{ml}$ $d^{\prime}$ hydrogène par heure et par g (poids sec) de biomasse bactérienne. 
- Les cyanobactéries génétiquement modifiées : ces organismes produisent naturellement de I'hydrogène, mais de façon discontinue et en petite quantité. Leur modification génétique, par introduction d'une hydrogénase (ferredoxine : $\mathrm{H}_{2}$ oxydoréductase) à côté de la ferredoxine : NADP oxydoréductase, permettrait, en réalisant la photolyse de l'eau, d'accroître les rendements dans des proportions économiquement intéres- santes. Un challenge de plus pour la biologie moléculaire.

Le département de l'Énergie des États-Unis consacre $^{24}$ environ 1 million de \$ US par an aux recherches sur la production de biohydrogène. Une installation expérimentale vient d'être mise en service à l'université de Hawaii pour tester la seconde filière.

24. J. Benemann, Hydrogen biotechnology : Progress and prospects, Nature Biotech., 14 - 1101-1103, 1996.

\section{Conclusions}

Au niveau mondial, 276 entreprises sont impliquées ${ }^{25}$ dans la production et la transformation des microalgues. Environ $1 / 3$ d'entre elles se consacrent à la production des espèces dominantes (Chlorella, Spirulina, Dunaliella, Scenedesmus) en systèmes ouverts, en Asie-Pacifique notamment. Même s'ils contribuent majoritairement à la production mondiale (environ 2000 t/an), ces systèmes ont atteint leurs limites techniques autant dans la variété des algues produites que dans les rendements. Dans ce contexte, la France ne s'intéresse guère à ces grandes productions en bassin ouvert, mais plutôt à des productions à haute technologie pour lesquelles elle serait mieux préparée. Une trentaine d'entreprises françaises sont impliquées dans l'exploitation des microalgues, soit $17 \%$ des entreprises mondiales (hors systèmes ouverts). II existe donc une véritable initiative industrielle nationale dans ce domaine, et il appartient d'autant plus aux établissements de recherche publics de l'accompagner qu'il s'agit le plus souvent de PME innovantes ayant peu de moyens à consacrer à la R\&D.

L'IFREMER dispose d'une compétence scientifique et d'une infrastructure de qualité dans quatre des principaux domaines concernés : chimie fine, aquaculture, environnement, génie des procédés de production. II a su les acquérir et les développer dans le cadre de ses missions en soutien des professions de l'aquaculture, et d'observation de l'environnement littoral. Des considérations plus prospectives l'ont, en outre, conduit à s'intéresser aux systèmes de production en conditions contrôlés, aux techniques de séparation et à la chimie fine. Cet ensemble de compétences et les infrastructures associées constituent des atouts au service des acteurs économiques des secteurs concernés, et ceci en dépit d'une forte dispersion géographique et thématique.

L'analyse de la spécificité de la recherche nationale nécessiterait une étude comparative des efforts en France et dans les autres pays (G7, Union européenne) que nous n'avons pas menée. Les pays les plus en pointe sont les États-Unis, Israël, le Japon et l'Australie, mais la recherche y est surtout le fait d'entreprises privées, ce qui rend son évaluation difficile en terme de niveau et d'échéance. Les pays européens leaders ont également développé des compétences sectorielles de bon niveau, que les collaborations transnationales permettent de valoriser. Les enjeux apparaissent importants : une course à l'innovation s'est engagée au niveau mondial en biotechnologie marine, course à laquelle la France doit participer d'une façon générale, et sur les microalgues en particulier.

Dans ce contexte, la présente analyse a permis d'identifier plusieurs orientations pour l'IFREMER :

- dans tous les domaines d'application, des progrès significatifs sont à attendre d'un accroissement de la qualité de la biomasse par une plus 
grande maîtrise technologique, physiologique et génétique des cultures. En permettant I'accès à la ressource, le génie des procédés appliqué à la conception des systèmes de production et de séparation représente un élément clé du dispositif, tant pour la recherche que pour les applications industrielles. L'accroissement des performances de production de molécules ciblées est un objectif économique. Une adaptation des outils de production à des espèces particulières permettra, en outre, de diversifier à la fois les ressources et les produits. La définition des conditions de culture (principaux paramètres, milieux, temps de séjour) les plus propices à la production des molécules ciblées est un des aspects importants. Enfin, il faudra définir et mettre en pratique des règles strictes portant sur la pureté des souches, leur préservation, et le contrôle des dérives génétiques par rafraîchissement périodique du génome une fois que l'on aura ciblé les espèces, puis les souches les plus intéressantes ;

- Dans le domaine de la chimie fine, les travaux doivent rester limités aux molécules pour lesquelles la compétitivité des microalgues est la plus forte (EPA, lipides complexes, substances bioactives), et aux espèces déjà connues, en étendant toutefois le champ de l'investigation à de nouvelles techniques de nature à accroître les performances de production au-delà du seuil économique (mutation aléatoire suivie de sélection, bioconversion, organotrophie, mutations dirigées). Les lipides constituent un thème fort compte tenu des déficits à prévoir à terme et de la spécificité des microalgues dans ce domaine. L'intérêt des substances bioactives des microalgues couramment cultivées doit être confirmé in vivo ;
- Dans le domaine de l'aquaculture, et de la conchyliculture en particulier, la place des microalgues présente un caractère stratégique, car non seulement celles-ci constituent une nourriture larvaire irremplaçable à ce jour, mais de surcroît, donnent lieu aujourd'hui à des applications économiques (télécaptage, affinage, verdissement) qui dégagent d'importantes valeurs ajoutées. Le recours aux écloseries-nurseries comme source de naissain d'huîtres est destiné à se généraliser, car lui seul permet de garantir la qualité génétique des animaux, et de tirer parti de la sélection des souches, notamment pour leur résistance aux épizooties. Dans le cadre de la maîtrise des techniques d'écloserie, la mise en œuvre de systèmes de production de microalgues mieux adaptés devrait permettre une stabilisation et un accroissement de la qualité du fourrage larvaire, et donc des produits finaux, avec diminution des coûts de production. Cette maîtrise de la qualité des fourrages devrait, en outre, contribuer à l'élucidation des besoins nutritionnels des larves, et au nécessaire développement des aliments inertes de substitution ;

- Dans le domaine de l'environnement, le développement des procédés de détection d'algues toxiques est identifié comme un important progrès, et devrait donner lieu à une action de recherche identifiée. La production des toxines est à envisager au même titre que celle des autres molécules bioactives, mais comporte des difficultés particulières liées au caractère fragile et peu productif des espèces concernées. Le traitement des effluents de pisciculture marine à terre ouvre des perspectives en introduisant le concept d'une aquaculture plus respectueuse de l'environnement. 


\section{Annexe I}

\section{Analyse des brevets}

Cette analyse a été réalisée à partir des données issues des centres de documentation de I'IFREMER à Brest, du Centre d'études et de valorisation des algues (CEVA) de Pleubian, et du répertoire Necton de la biotechnologie des microalgues, 1995.

L'analyse statistique par date de dépôt montre une reprise de dépôt de brevets ces dernières années, après un fléchissement fin 1980. Plus de 300 brevets, qui se référent aux biotechnologies des microalgues, ont été déposés ces 25 dernières années (fig. I). La base WPI (World Patent Index) fait état de 178 brevets de référence, dont la répartition par pays est donnée par la figure II.
Sur le plan thématique, la couverture brevet détaillée dans le tableau ci-dessous laisse apparaître une nette dominance des revendications relatives aux systèmes de culture et de récolte (environ la moitié des brevets) dont environ $20 \%$ concerne les systèmes de production en photobioréacteurs. Le domaine de l'environnement constitue un pôle d'intérêt croissant où il conviendrait de mieux identifier la part " microalgues marines ». Le secteur alimentaire (aliment aquacole, complément nutritionnel et nutraceutique) représente un créneau de valorisation reposant sur des spécificités métaboliques variées : lipides polyinsaturés à longue chaîne, pigments, antioxydants.

\begin{tabular}{|c|c|}
\hline Système de culture et de récolte & 131 \\
\hline Système de production par photobioréacteur & 24 \\
\hline $\begin{array}{l}\text { Environnement (traitement des effluents, } \\
\text { élimination charge organique, xénobiotique) }\end{array}$ & 34 \\
\hline Alimentation, diététique & 20 \\
\hline Aliment aquacole & 4 \\
\hline $\begin{array}{l}\text { Agriculture (biofertiliseur, } \\
\text { activateur de croissance, phytoeffecteur) }\end{array}$ & 6 \\
\hline Colorants & $\begin{array}{c}42, \\
\text { dont } \beta \text { - carotène (21), phycocyanine (13), } \\
\text { astaxanthine (4), chlorophylle (1) }\end{array}$ \\
\hline Lipides et dérivés & $\begin{array}{c}22, \\
\text { dont glycérol (7), alcool et polyols (2), EPA (5), } \\
\text { AA (1), VitE (1), Ac. gras (1), glycolipides (1), } \\
\text { dérivés lipidiques (4) }\end{array}$ \\
\hline Protéines, enzymes, acides aminés & 3 \\
\hline Génie génétique, amélioration de souches & 4 \\
\hline Énergie (méthane, hydrocarbure, hydrogène) & 6 \\
\hline Polysaccharides & 7 \\
\hline
\end{tabular}

Analyse statistique des brevets relatifs aux microalgues par domaines ou produits (source : répertoire Necton de la biotechnologie des microalgues, 1995). 


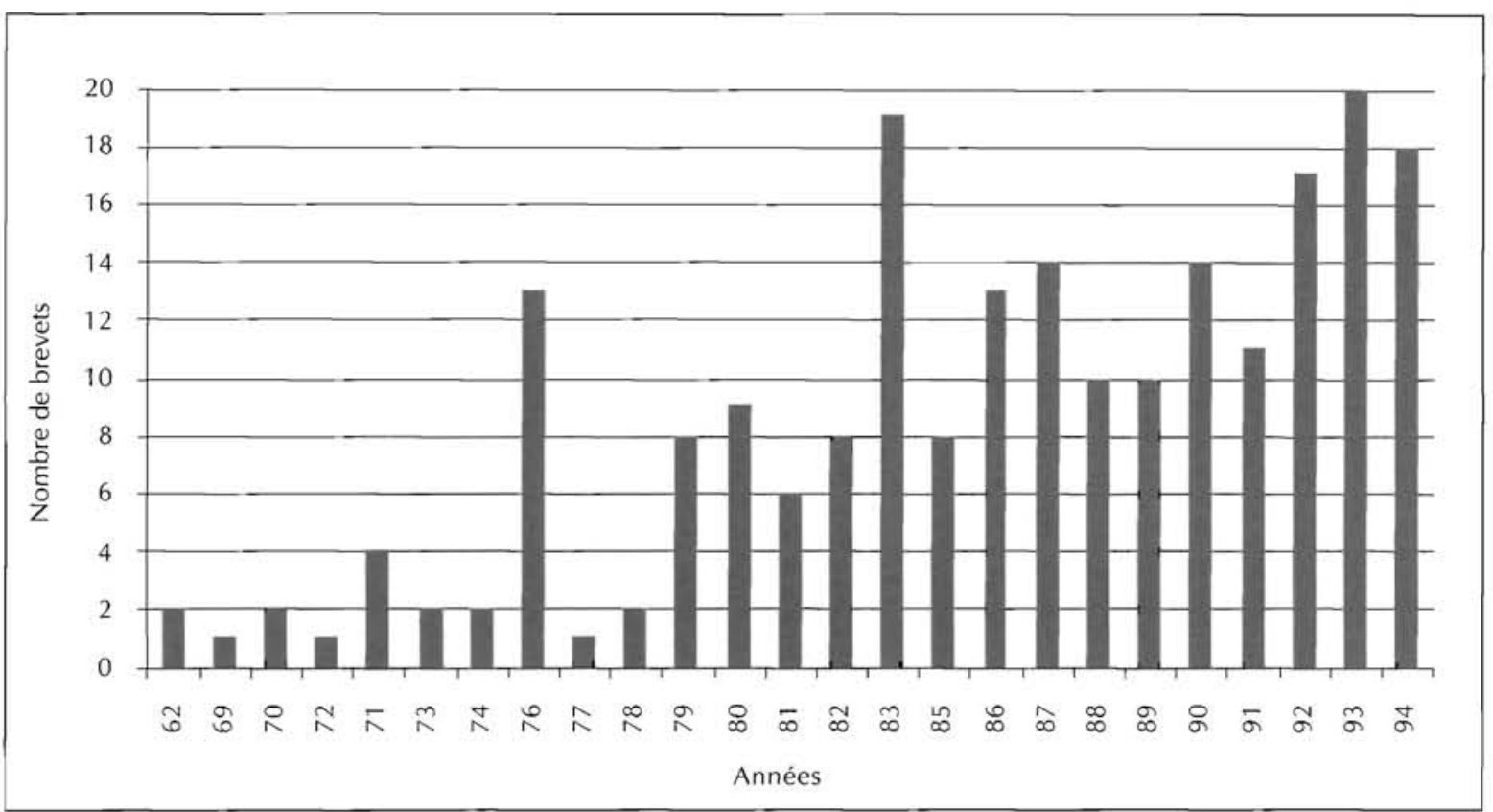

Figure I - Nombre de brevets relatifs aux microalgues par année de dépôts (source : WPI).

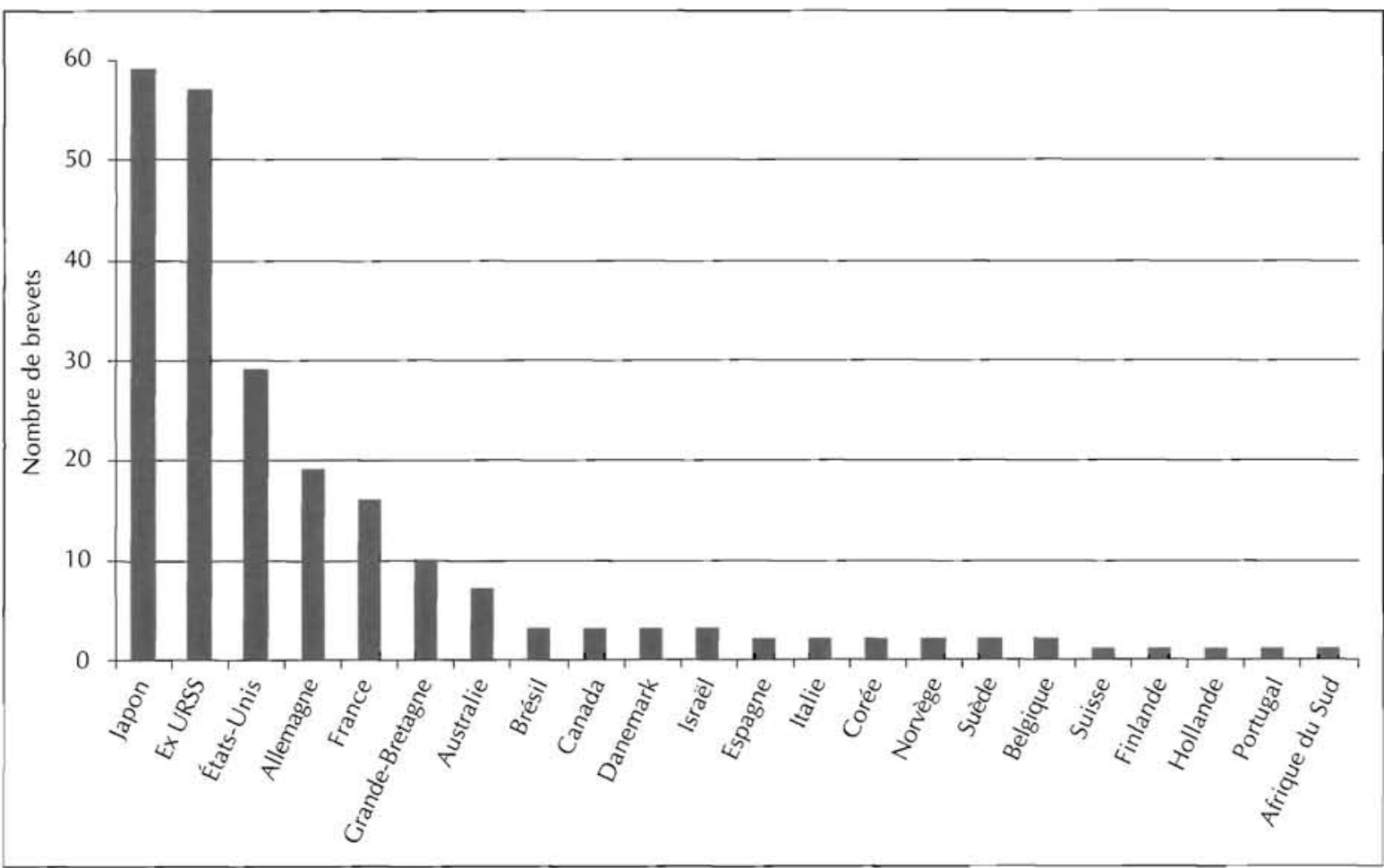

Figure II - Distribution par pays des brevets relatifs aux microalgues en 1995 (source : répertoire Necton de la biotechnologie des microalgues, 1995). 


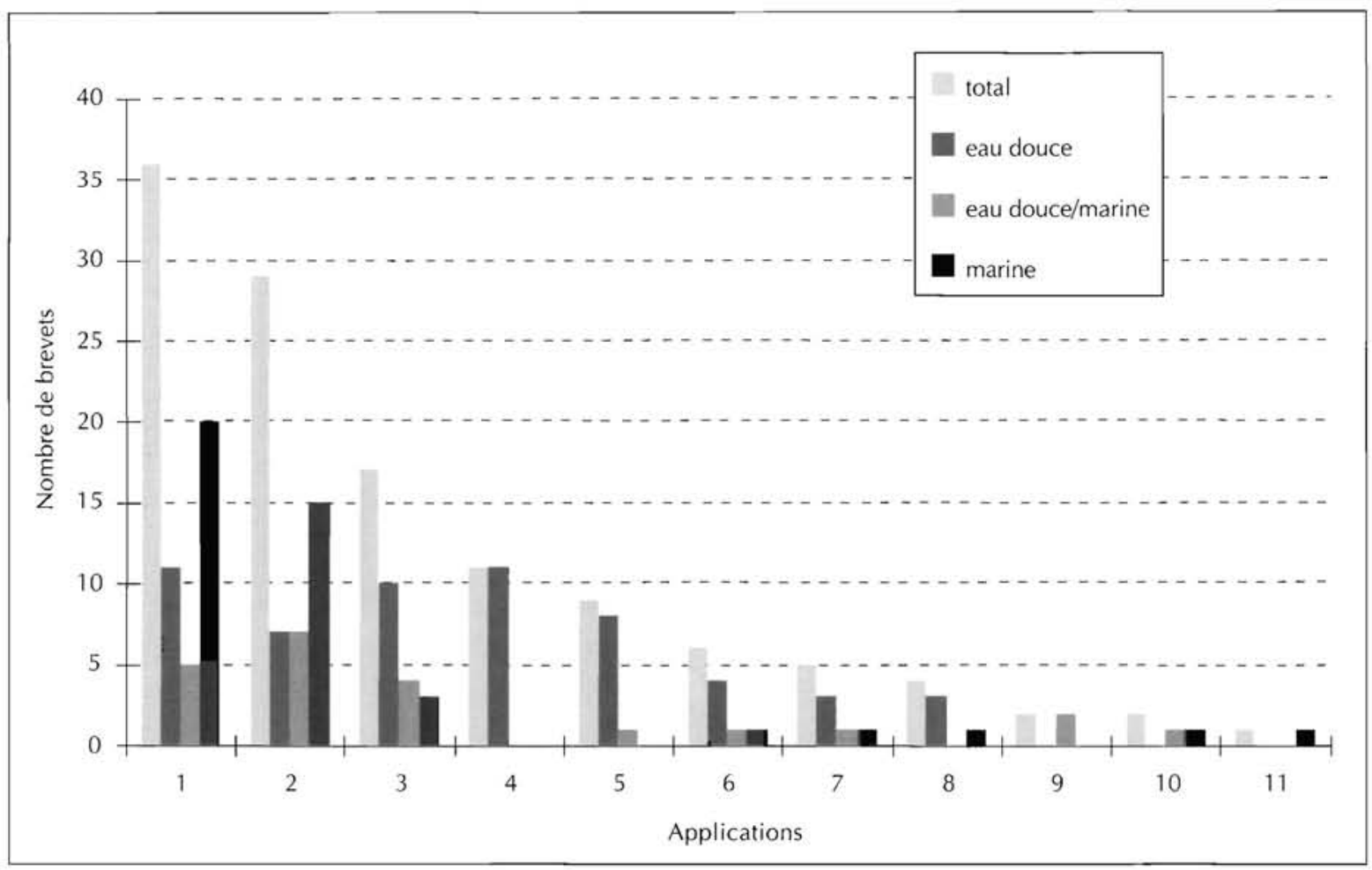

Figure III - Distribution des brevets relatifs aux microalgues par application (ibid.). 1 : Lipides (EPA, DHA, ARA, PUFA, stérols, glycolipides), 2 : Aquaculture biomasse, 3 : Pigments ( $\beta$-carotène, astaxanthine, zéaxanthine, lutéine, phycocyanine, chlorophylle, caroténoïdes), $4:$ Traitements des effluents, $5:$ Agriculture (N2, biofertilisants, NH4), $6:$ Polysaccharides, $7:$ Enzymes, $8:$ Vitamines (Vit E., B6, NAD), 9 : Antibiotiques, 10 : Diététique, 11 : Lysine.

L'analyse des brevets fait référence à une douzaine de classes de microalgues et mentionne environ 90 genres ou espèces répartis pour moitié entre microalgues d'eau douce et marines.

Il est cependant à noter que, sur ce total, seul environ un quart des espèces sont considérées comme ayant un statut " commercial ". La figure III en illustre le potentiel d'utilisation et fait ressortir la spécificité marine pour les applications aquacoles et les valorisations des acides gras à longue chaîne. 
Annexe II

\section{Analyse des publications}
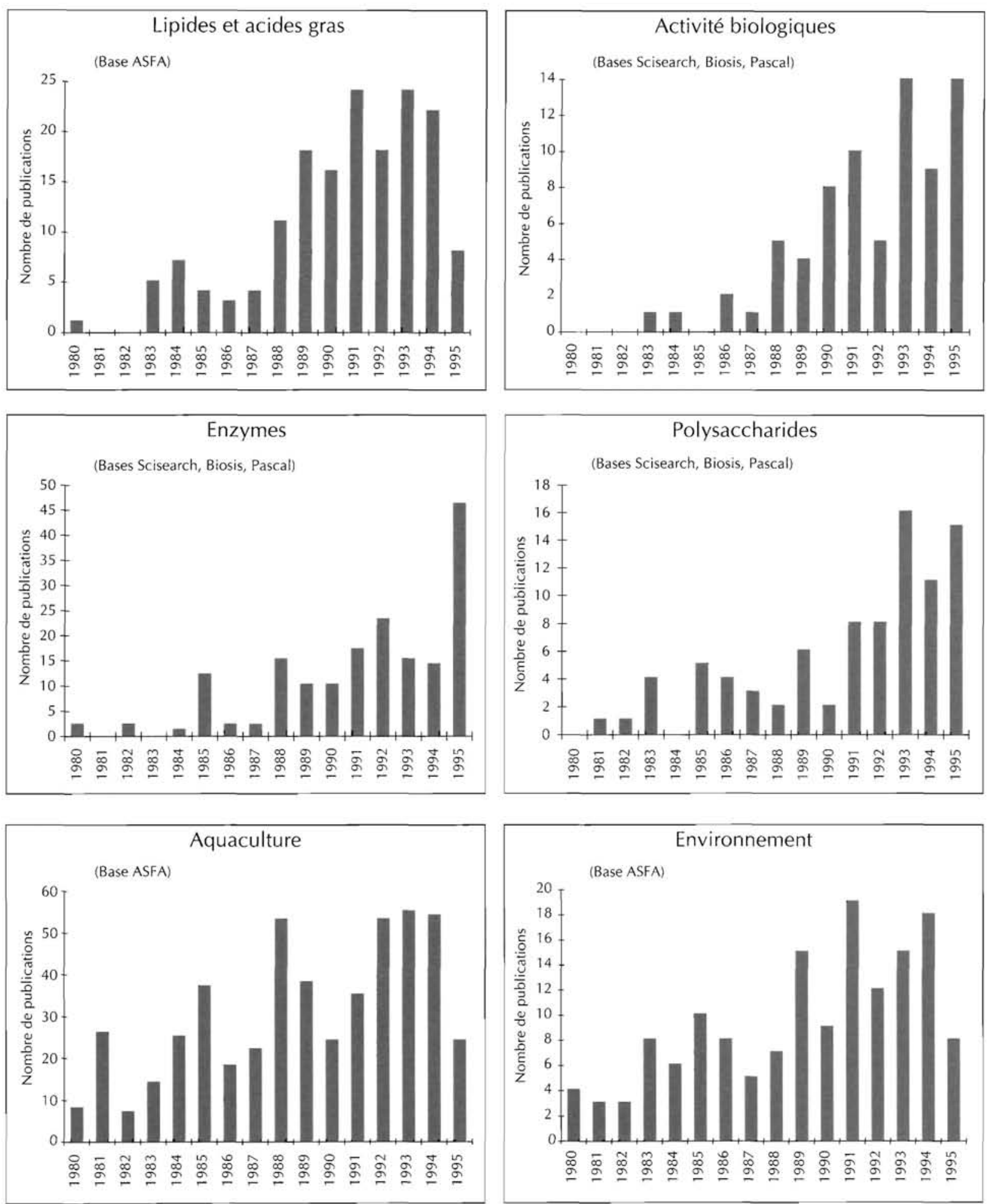

Figure IV - Évolution du nombre de publications scientifiques relatives aux microalgues pour les différents sujets d'intérêt (banques de données Asfa, Scisearch, Biosis, Pascal). 
Réalisation, mise en page : XLC (02 983050 07)

Achevé d'imprimer sur les presses de Cloître Imprimeurs

ISSN 1279-8339

ISBN 2-905434-82-1 / Dépôt légal 4e trimestre 1997

(c) 1997, IFREMER. Tous droits de reproduction, même partielle, par quelque procédé que ce soit, sont réservés pour tous pays. 